\title{
Lightweight, Durable, and Multifunctional Electrical Insulation Material Systems for High Voltage Applications
}

\author{
Euy-Sik Eugene Shin, ${ }^{1}$ and Daniel A. Scheiman ${ }^{2}$ \\ Ohio Aerospace Institute, NASA Glenn Research Center, 21000 Brookpark Rd., MS 49-1, Cleveland, OH 44135, \\ USA \\ Maricela Lizcano ${ }^{3}$ \\ NASA Glenn Research Center, 21000 Brookpark Rd., MS 106-5, Cleveland, OH, 44135, USA
}

\begin{abstract}
Newly developed multilayer structures of well-known polymer insulation materials significantly improved dielectric breakdown voltage, $V_{B}$, or dielectric strength, $K$, if wellbonded, when compared to those of single material insulations or the commercial SOA systems, such as Teflon-Kapton-Teflon (TKT), at the same overall thickness. To date, the greatest improvement of the new structures from a few candidate materials, including various types of Kapton PIs and PFA or PET as bond layer (BL), was about $61 \%$ higher than that of the Kapton PI alone films, 40.1 vs. $24.9 \mathrm{kV}$, which was translated to $86.3 \%$ decrease in insulation thickness, thus significant volume and weight reduction of the final system. However, it was of interest to note that most improvements of the multilayer structures occurred at thicker overall thicknesses, above $\sim 0.15 \mathrm{~mm}$. Extensive analyses also showed that $K$ of the multilayer structures increased with (i) decreasing individual layer thickness regardless of material type, (ii) increasing total accumulated thickness of PI or overall PI/BL ratio, and (iii) increasing number of interface or total number of layers, but only above the aforementioned overall thickness limit. Increases in $V_{B}$ of the multilayer structures were directly correlated with damage evolution and failure mode. With further material-designprocess optimizations of the multilayer structures, it was expected to achieve other multifunctionalities, such as high partial discharge (PD) resistance, improved durability, EMI shielding, and high thermal dissipation in addition to high dielectric strength. These new structures can be used in various high voltage and high temperature applications, such as future hybrid or all electric aircraft wiring and power transmission as well as many other nonaerospace high power cables, electronic parts and components, printed circuit board, and so forth. The multilayer insulation system can be easily processed and manufactured with various conductor types via calendaring, compression-molding, stamping, laminating, vacuum-bagging and autoclaving, or 3D printing, even for complex 3-D components. Based on their unique structural configurations and potential capabilities, the new insulation system was identified as micro-multilayer multifunctional electrical insulation (MMEI). Patent application of the MMEI concept and current design configurations was filed for a 1-year provisional application (OAI-58834, Serial No.: 62/659,234), pending conversion to a U.S. utility application. This paper presents details of the MMEI structures, their dielectric performance analyses, potential mechanisms, and commercial scaleup feasibility assessment.
\end{abstract}

\section{Nomenclature}

ASTM = American Society for Testing and Materials

$B L=$ Bond Layer

$B N \quad=$ Boron Nitride

\footnotetext{
${ }^{1}$ Principal Scientist, Research Team Manager-Materials, Ohio Aerospace Institute (OAI). On-site contract researcher at NASA GRC. Non-AIAA member.

${ }^{2}$ Senior Researcher, OAI. On-site contract researcher at NASA GRC. Non-AIAA member.

${ }^{3}$ Research Materials Engineer, Materials Chemistry \& Physics Branch, Materials \& Structures Division, NASA GRC. Non-AIAA member.
}

American Institute of Aeronautics and Astronautics 


$\begin{array}{ll}C I V & =\text { Corona Inception Voltage } \\ D Z W & =\text { Damage Zone Width } \\ E C P I & =\text { Electrically Conductive Polyimide } \\ F E & =\text { Finite Element } \\ H F & =\text { High Frequency } \\ H V & =\text { High Voltage } \\ K & =\text { Dielectric Strength } \\ K B F & =\text { Kapton Bagging Film } \\ m D S C & =\text { Modulated Differential Scanning Calorimetry } \\ M M E I & =\text { Micro-multilayer Multi-functional Electrical Insulation } \\ O M & =\text { Optical Microscopy } \\ P D & =\text { Partial Discharge } \\ P E T & =\text { Polyethylene terephthalate } \\ P F A & =\text { PerFluoroAlkoxy } \\ P I & =\text { Polyimide } \\ P P & =\text { Partial Perforation } \\ P T F E & =\text { Polytetrafluoroethylene } \\ S O A & =\text { State-of-the-Art } \\ T G A & =\text { Thermogravimetric Analysis } \\ T H P & =\text { Through-Hole Perforation } \\ T K T & =\text { Teflon-Kapton-Teflon } \\ T C P I & =\text { Thermally Conductive Polyimide } \\ V_{B} & =\text { Dielectric Breakdown Voltage }\end{array}$

\section{Introduction}

$\mathrm{D}$ EVELOPMENT and demonstration of electric propulsion technologies for aircrafts have been one of the major thrusts of NASA Aeronautics Research Mission Directorate (ARMD) via various programs (Ref. [1-6]) because of their potential benefits including fewer emissions, improved fuel economy, quieter flight, improved efficiency and maneuverability, and reduced maintenance costs and improved reliability. The electric propulsion which will allow better utilization of infrastructure can also be a breakthrough technology for the future urban air mobility (UAM) project in emerging aviation markets (EAM) (Ref. [7-8]). The main challenges in designing electric or hybrid-electric propulsion were to meet the high power requirement and to reduce weight of subsystems and cables, and employing high voltage high frequencies system was preferred and more feasible option as explained in Ref. [2,9,11]. For instance, future large capacity commercial electric aircraft will ultimately require more than $\sim 20$ MW power distribution with high voltage (e.g., $\mathrm{VAC}_{\max }=20 \mathrm{KV}, 3$-phase, but must design for $>40 \mathrm{KV}$ ) and variable frequency of $400-4000 \mathrm{~Hz}$.

As summarized in Ref. [2], a few years ago, NASA-GRC research team initiated a project, 'High Voltage Hybrid Electric Propulsion (HVHEP)' under the NASA's Convergent Aeronautics Solutions (CAS) program to tackle the multifaceted challenges in which our materials team performed on developing new HV lightweight insulation materials or structures. It was generally agreed in the community that current high voltage cable technologies were not suitable for such high altitude airplane operations. Electrical, thermal, and mechanical stresses decrease the performance life of insulating materials particularly including corona discharge contributors to material aging and failure via material carbonization and material degradation from ozone generation, higher voltages and frequencies causing increased electrical and thermal stresses, and system operating temperature in combination of thermal cycling which may lead to thermal degradation (Ref. [10-13]). Initial materials efforts in the CAS project focused on developing an insulation that can be lightweight, durable, high temperature capable, while electrically stable with high dielectric strength and PD resistance via multidisciplinary approach which involved materials R\&D including SOA materials, physics-based analyses and modeling, and power cable prototype development (Ref. [14]). Figure 1 showed the original design concept of new insulation structure, so-called multilayer functional insulation system (MFIS), on a flat conductor such as a power transmission bus bar. Various material types with different functionalities, particularly for dielectric strength and thermal management, were employed assuming that resistive joule heating under such a high voltage high power transmission would be considerably high. Even though our initial electrothermal FE modeling including radiation and convection on a flat conductor with 3-layer polymer insulation indicated that the estimated joule heating was rather small, less than $70{ }^{\circ} \mathrm{C}$, regardless of voltage or frequency within the target ranges, thermal management of heat dissipation was still relevant for the application since the power cable could pass

American Institute of Aeronautics and Astronautics 
by high heat sources, e.g., as high as $400{ }^{\circ} \mathrm{C}$ for certain generators (Ref. [11]). Consequently, the new MMEI structures were driven from the original design concept.

Since then, the project has been transitioned to the Transformational Tools and Technology (TTT) program to continue developing innovative concepts for future hybrid electric aircraft. Both CAS and TTT are part of NASA's Transformative Aeronautics Concept Program (TACP) under Aeronautics Research Mission Directorate (ARMD). This paper presents progresses in development of the new MMEI structures as potential insulation candidate for future hybrid or all-electric aircrafts and other high voltage applications.

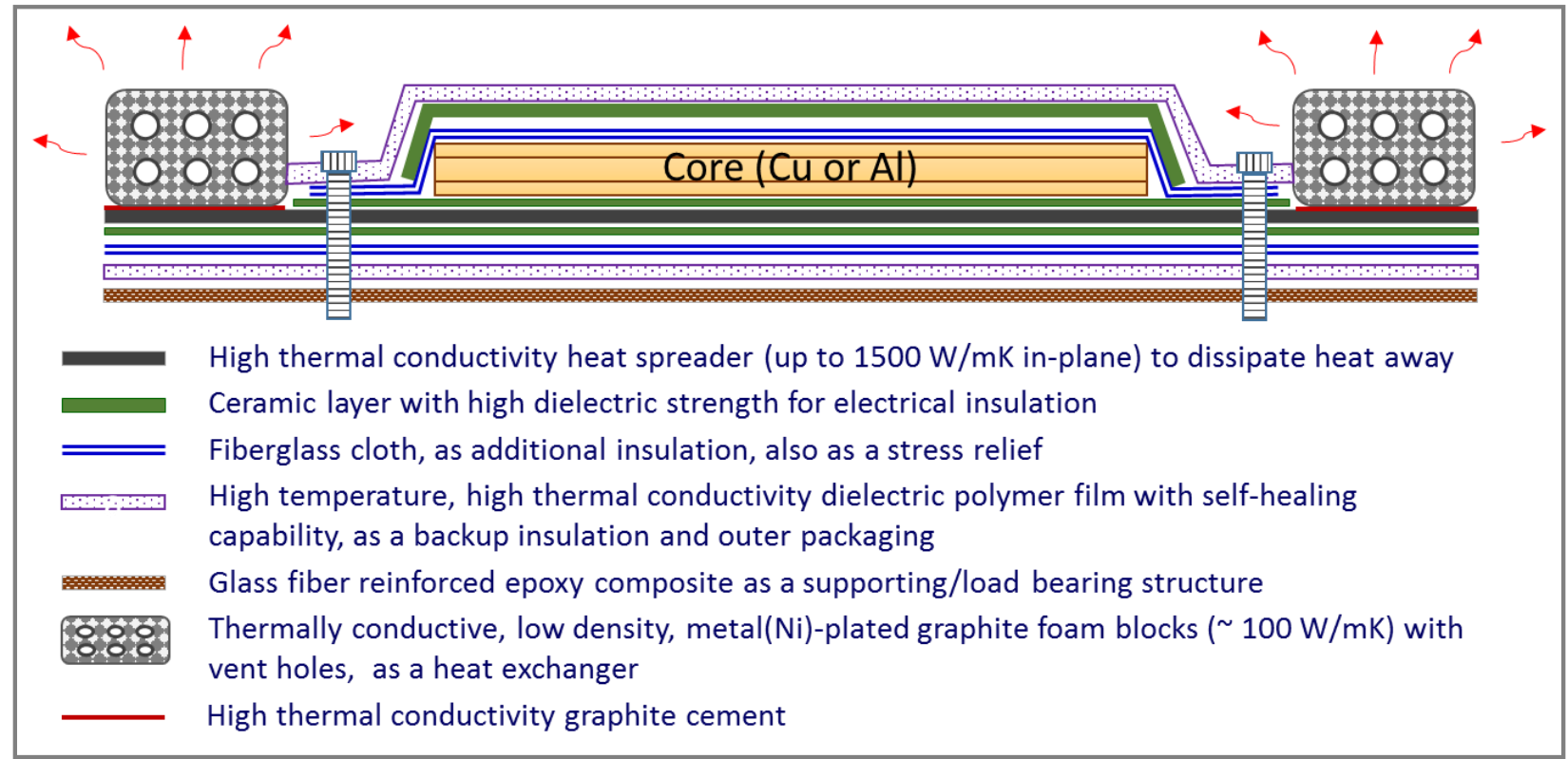

Figure 1. Schematics of the original MFIS designed for high voltage high power bus bar.

\section{Experimental}

\section{A. Materials}

The SOA dielectric insulation materials used in this study included various commercial products as follows:

- 1 mil, 2 mil, and 5 mil thick Thermalimide Kapton bagging film (KBF) from Airtech International, Inc.

- Kapton® PI films from DuPont

- $0.3 \mathrm{mil}, 1 \mathrm{mil}$, and 5 mil thick HN, a tough, aromatic film: $30 \mathrm{HN}, 100 \mathrm{HN}$, and $500 \mathrm{HN}$, respectively

- 0.5 mil thick HPP-ST, the same tough film as HN with superior dimensional stability and adhesion characteristics: 50HPP-ST

- 1 mil thick CRC corona resistant films: 100CRC

- 0.5 mil and 1 mil thick PFA films from Chemours

- 2 mil and 5 mil thick PFA films from McMaster-Carr

- 2 mil thick virgin Teflon ${ }^{\circledR}$ PTFE films from McMaster-Carr

- 2 mil thick PET, Mylar A polyester films from Tekra

PFA, PTFE, and PET are semicrystalline polymers which were used for heat fuse-bonding. Melting temperature of PFA by mDSC was somewhat thickness dependent, e.g., $305,309,311^{\circ} \mathrm{C}$ for 5 mil, 1 mil, 0.5 mil, respectively, but the peak ending temperature of the melting peak was $320^{\circ} \mathrm{C}$ regardless of thickness. Thermal degradation onset temperature of PFA by TGA was $548-550{ }^{\circ} \mathrm{C}$ regardless of thickness. Melting temperature of 2 mil thick PTFE was about $327^{\circ} \mathrm{C}$ which was slightly higher than those of PFA. Melting temperature of 2 mil thick PET film was $255-$ $257^{\circ} \mathrm{C}$ with the peak ending temperature at $270{ }^{\circ} \mathrm{C}$ and its thermal degradation onset temperature was $422-434^{\circ} \mathrm{C}$.

In addition, thermally conductive PI (TCPI), 2 mil thick, and electrically conductive PI (ECPI), 1 mil thick, films (purchased from McMaster-Carr) were tested for MMEI systems for potential multi-functionality, e.g., heat dissipation or corona resistance, respectively. The SOA heat spreader eGRAF® Spreadershield ${ }^{\mathrm{TM}}$ SS1500 flexible graphite, 1.5 mil thick, from GrafTech which offers $1500 \mathrm{~W} / \mathrm{mK}$ in-plane thermal conductivity and $3.4 \mathrm{~W} / \mathrm{mK}$ through-plane thermal conductivity was also evaluated for the latter functionality.

American Institute of Aeronautics and Astronautics 


\section{B. Fabrication of Dielectric Strength Test Samples}

The dielectric strength test samples, typically $1.0 \times 1.25$ inch, especially testing in oil bath, were fabricated by a simple compression molding. In most cases, coupons of either $2 \times 1.25$ inch or $3 \times 1.25$ inch in dimensions were molded and cut into two or three test samples. For the MMEI configurations having PI layer on the outermost layers, the selected insulation films per lay-up configuration were laid up carefully on 1/16" thick aluminum sheet after cleaned with isopropyl alcohol and dried. In the case of the MMEI configurations having the meltable PFA layer on outermost layers, additional layers of 5 mil thick PI film with 9/32 inch dia. holes in the middle which were placed by 5 mil thick copper disc as a part of conducting electrode were employed at both sides. The lay-up was then sandwiched with another 1/16" thick aluminum sheet and compressed with binder clips (typically 2 small and 2 large). The assembly was placed in an air-circulated oven at room temperature, heated to a target temperature for proper melting and flowing of the bond layer for optimum fuse-bonding. Temperature of the assembly was monitored closely during the entire process. All of the first batch MMEI coupons were fabricated with the above condition. However, for the second batch coupons, more uniform compression was achieved by using 3/16" thick A2 tool steel molding plates instead of aluminum plates, and high compression loading at the processing temperature was controlled/maintained by Inconel high temperature sealing clip (rated to $370{ }^{\circ} \mathrm{C}, 1.5 \mathrm{lbs}$ clamping force per clip), as illustrated in Figure 2 .

The optimum heat fuse-bonding conditions used for two different bond layers were as follows; (i) $10 \mathrm{~min}$ after reaching $350{ }^{\circ} \mathrm{C}$ in the coupon assembly after setting the oven at $660{ }^{\circ} \mathrm{F} / 349^{\circ} \mathrm{C}$ (typically reached $~ 352.4$ to 352.8 ${ }^{\circ} \mathrm{C}$ after 10 min dwell) for PFA and (ii) 10 min after reaching $270{ }^{\circ} \mathrm{C}$ in the coupon assembly after setting the oven @ $518^{\circ} \mathrm{F} / 270^{\circ} \mathrm{C}$ for PET, under uniform compression loading of about 8 to 8.4 psi using either 14 clips on $2 \times 1.25$ inch coupon or 20 clips on $3 \times 1.25$ inch coupon.

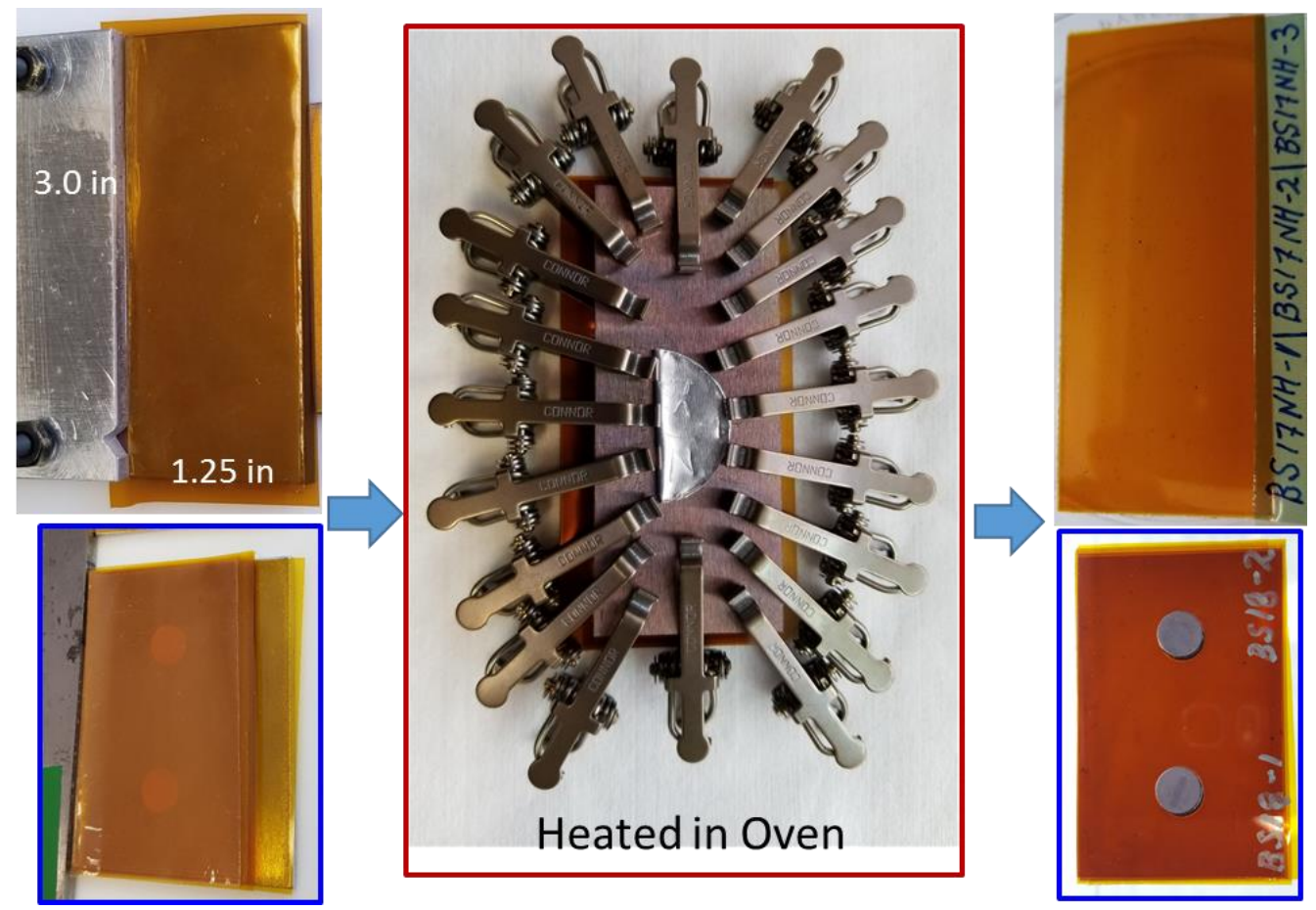

Figure 2. Simple fabrication procedure for dielectric test specimens of MMEI structures.

\section{Dielectric Strength Testing}

In the feasibility study, the main electrical property and performance monitored for various insulation materials and structures was dielectric breakdown voltage or dielectric strength which was used for material screening. Figure 3 shows the test equipment (Model DT2-60-20-SR-P-C, Sefelec Eaton, France) with key testing capabilities. It also shows one of the six available fixtures (Model TF1 through TF6, Phenix Technologies, Inc, MD) used in an oil bath (Model D149, Phenix Tech.) based on ASTM D149. To keep consistency in candidate screening, the test conditions were standardized for most samples which included simple AC ramp at $0.6 \mathrm{kV} / \mathrm{s}$ with TF3 fixture (opposing cylindrical rods, $6.4 \mathrm{~mm} / 0.25$ inch in diameter with edges rounded to $0.8 \mathrm{~mm} / 0.0313$ inch in radius) in oil bath (PM- 125 phenylmethylsiloxane). The oil bath was not to simulate any service condition, but practical and effective in preventing flash over breakdown or voltage leaking or arcing around the small test specimens. The samples, especially

American Institute of Aeronautics and Astronautics 
with higher $V_{B}$, have to be larger than 4 - 5 inch dia. if they were to test in air. All dielectric strength testing was performed at room temperature. A known reference sample was tested before and after every actual sample group to ensure consistent equipment performance. Thickness of test samples was measured with a high resolution micrometer (Starrett No. 216) with $\pm 0.001 \mathrm{~mm}$ resolution at constant preset force. Besides of flat sheet samples, actual electric wire/cable or custom-designed 3 dimensions samples were tested using the same standardized conditions after optimizing sample configuration which will be discussed in later sections. After dielectric strength testing, all tested samples were examined with an optical microscopy to determine failure modes in terms of voltage and current direction, from voltage-in to voltage-out surface.

This equipment was also used to measure corona inception voltage (CIV) based on ASTM D1868 after installing a high voltage resistor between the sample and the ground which was used to monitor micro-voltage changes via voltmeter at the onset of corona PD. Voltage endurance testing of primary insulation candidates to corona PD based on ASTM D2275 will be attempted with this test equipment in the future.

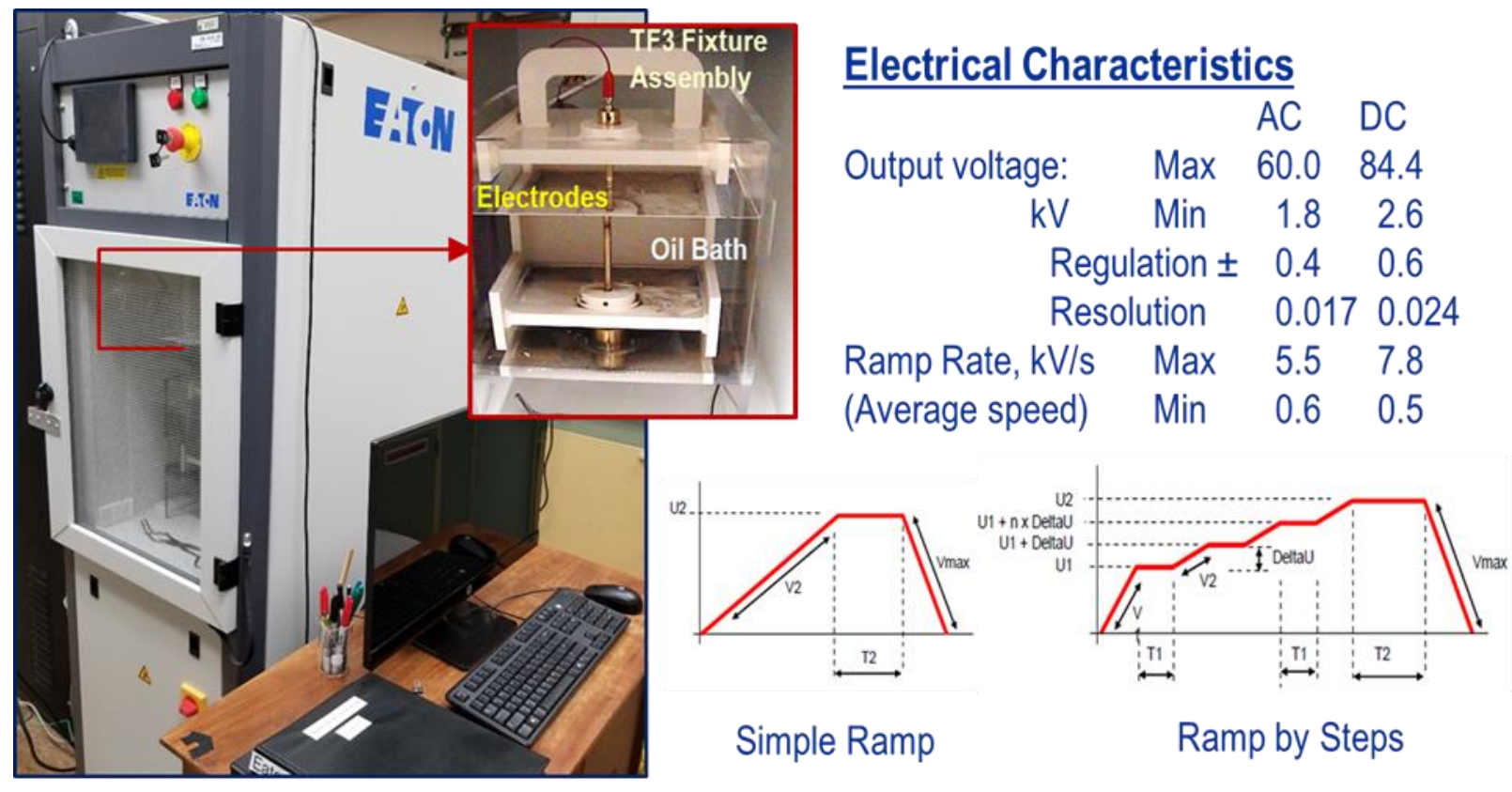

Figure 3. Dielectric Strength Test Equipment and Capabilities.

\section{Results and Discussions}

\section{A. Status of the Invention}

Figure 4 summarizes the overall electrical insulation performance of the newly developed MMEI structures in terms of dielectric breakdown voltage, $V_{B}$, as a function of overall thickness in comparison with that of the SOA insulation materials including Kapton PI, PFA, PET, or a typical TKT system. Various MMEI structures in the plot differed by either insulation materials used in their structures or batch number while different ID numbers indicated different structural configurations as described in detail in Table 1. The asterisk mark used in the layer configurations indicated thickness in mils (1/1000 of inch) and the subscripted numbers after bracket indicated number of repeats of the layup sequence in the bracket. In the case of Kapton PI films, the plotted data set included both literature values (Ref. [15]) and in-house test results under the similar test conditions from various types including KBF, HN, HPP-ST, and CRC, covering a wide range of thickness from 0.008 to $0.76 \mathrm{~mm}$ even though Figure 4 only showed up to $0.5 \mathrm{~mm}$ for clarity. PFA data set was mostly from in-house test results except $(3.175 \mathrm{~mm}, 68.9 \mathrm{kV})$ data point from literature (Ref. [16]). Dashed lines were the best curve-fit trendlines for either Kapton PI or PFA films, and note that they fit with different equation form, logarithm or power. To date, the greatest improvement in $V_{B}$ of the new systems compared to the Kapton PI alone films including the SOA TKT system based on same overall thickness was about $61 \%$ from BS17NH, but general improvement occurred mostly at thicker overall thicknesses, above $\sim 0.15 \mathrm{~mm}$. Another way to signify the increase in $V_{B}$ of the new systems can be comparing its required overall thickness for a given voltage with that of the SOA material, such as Kapton PI. For example, the MMEI structures BS17NH with overall thickness of $0.225 \mathrm{~mm}$ can withstand high voltage up to $\sim 40 \mathrm{kV}$, but for the Kapton PI film, it requires 1.62

American Institute of Aeronautics and Astronautics 
$\mathrm{mm}$ overall thickness based on the trend line of Kapton PI, $\mathrm{y}=7.6412 \ln (\mathrm{x})+36.3$, from the plot. Thus, there will be $86.3 \%$ decrease in insulation thickness if the Kapton PI were replaced with the new insulation system. Therefore, the overall weight and volume of the final electric power transmission cable will be decreased significantly.

Table 1. Layer configurations of various MMEI structures including overall thickness.

\begin{tabular}{|c|c|c|c|c|c|c|}
\hline \multirow{3}{*}{\multicolumn{2}{|c|}{ Coupon ID }} & \multirow{3}{*}{ Layer Configuration } & \multicolumn{3}{|c|}{ Overall Thickness } & \multirow{3}{*}{$\begin{array}{c}\text { Total \# } \\
\text { of } \\
\text { layers }\end{array}$} \\
\hline & & & \multicolumn{2}{|c|}{ Design } & \multirow{2}{*}{\begin{tabular}{|c|} 
Processed \\
$\mathrm{mm}$ \\
\end{tabular}} & \\
\hline & & & mil & $m \boldsymbol{m}$ & & \\
\hline \multirow{16}{*}{ 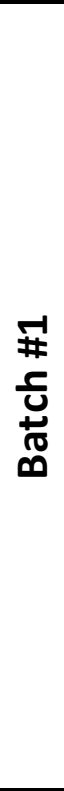 } & BS11 & $5 * \mathrm{PFA} / 5^{*} \mathrm{KBF} / 5^{*} \mathrm{PFA}$ & 15 & 0.381 & 0.363 & 3 \\
\hline & BS12 & $5 * \mathrm{KBF} / 5 * \mathrm{PFA} / 5 * \mathrm{KBF}$ & 15 & 0.381 & 0.378 & 3 \\
\hline & BS13 & 2*PFA/5*KBF/5*PFA/5*KBF/2*PFA & 19 & 0.483 & 0.455 & 5 \\
\hline & BS14 & 5*KBF/5*PFA/1*KBF/5*PFA/5*KBF & 21 & 0.533 & 0.478 & 5 \\
\hline & BS15 & {$[2 * \mathrm{PFA} / 2 * \mathrm{KBF}]_{3} / 2 * \mathrm{PFA}$} & 14 & 0.356 & 0.363 & 7 \\
\hline & BS16 & $1 * \mathrm{KBF} / 2 * \mathrm{PFA} / 2 * \mathrm{KBF} / 5^{*} \mathrm{PFA} / 2 * \mathrm{KBF} / 2 * \mathrm{PFA} / 1 * \mathrm{KBF}$ & 15 & 0.381 & 0.345 & 7 \\
\hline & BS17 & {$[1 * \mathrm{KBF} / 2 * \mathrm{PFA}]_{4} / 1 * \mathrm{KBF}$} & 13 & 0.330 & 0.338 & 9 \\
\hline & BS17N & {$[1 * \mathrm{KBF} / 1 * \mathrm{PFA}]_{4} / 1 * \mathrm{KBF}$} & 9 & 0.229 & 0.233 & 9 \\
\hline & BS18 & {$[0.5 * \mathrm{PFA} / 1 * \mathrm{KBF}]_{6} / 0.5 * \mathrm{PFA}$} & 9.5 & 0.241 & 0.252 & 13 \\
\hline & BS19 & {$\left[1 * \mathrm{KBF} / 0.5^{*} \mathrm{PFA}\right]_{4} / 1 * \mathrm{KBF}$} & 7 & 0.178 & 0.178 & 9 \\
\hline & BS20 & {$\left[0.3 * \mathrm{HN} / 0.5^{*} \mathrm{PFA}\right]_{16} / 0.3 * \mathrm{HN}$} & 13.1 & 0.333 & 0.350 & 33 \\
\hline & BS20S & {$\left[0.3 * \mathrm{HN} / 0.5^{*} \mathrm{PFA}\right]_{4} / 0.3 * \mathrm{HN}$} & 3.5 & 0.089 & 0.089 & 9 \\
\hline & BS21 & {$\left[0.5^{*} \mathrm{HPP} / 0.5^{*} \mathrm{PFA}\right]_{9} / 0.5^{*} \mathrm{HPP}$} & 9.5 & 0.241 & 0.254 & 19 \\
\hline & BS22 & {$\left[0.5^{*} \mathrm{HPP} / 1^{*} \mathrm{PFA}\right]_{9} / 0.5 * \mathrm{HPP}$} & 14 & 0.356 & 0.386 & 19 \\
\hline & BS23N & {$[1 * \mathrm{KBF} / 2 * \mathrm{PET}]_{4} / 1 * \mathrm{KBF}$} & 13 & 0.330 & 0.158 & 9 \\
\hline & BS23 & {$[1 * \mathrm{KBF} / 2 * \mathrm{PET}]_{4} / 1 * \mathrm{KBF}$} & 13 & 0.330 & 0.210 & 9 \\
\hline \multirow{12}{*}{ 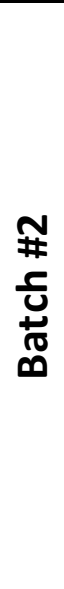 } & BS12 & $5 * \mathrm{KBF} / 5 * \mathrm{PFA} / 5^{*} \mathrm{KBF}$ & 15 & 0.381 & 0.343 & 3 \\
\hline & BS17NH & {$[1 * \mathrm{HN} / 1 * \mathrm{PFA}]_{4} / 1 * \mathrm{HN}$} & 9 & 0.229 & 0.225 & 9 \\
\hline & BS17NC & {$[1 * \mathrm{CRC} / 1 * \mathrm{PFA}]_{4} / 1 * \mathrm{CRC}$} & 9 & 0.229 & 0.242 & 9 \\
\hline & BS17NHT & $2 * \mathrm{PTFE} / 1 * \mathrm{PFA} /[1 * \mathrm{HN} / 1 * \mathrm{PFA}]_{4} / 1 * \mathrm{HN}$ & 12 & 0.305 & 0.310 & 11 \\
\hline & \begin{tabular}{|l|} 
BS19 \\
\end{tabular} & {$[1 * \mathrm{KBF} / 0.5 * \mathrm{PFA}]_{4} / 1 * \mathrm{KBF}$} & 7 & 0.178 & 0.173 & 9 \\
\hline & BS20S & {$\left[0.3^{*} \mathrm{HN} / 0.5^{*} \mathrm{PFA}\right]_{4} / 0.3^{*} \mathrm{HN}$} & 3.5 & 0.089 & 0.092 & 9 \\
\hline & BS20SR & {$[0.3 * \mathrm{HN} / 1 * \mathrm{PFA}]_{4} / 0.3 * \mathrm{HN}$} & 5.5 & 0.140 & 0.149 & 9 \\
\hline & BS20ST & {$[0.3 * \mathrm{HN} / 2 * \mathrm{PFA}]_{4} / 0.3 * \mathrm{HN}$} & 9.5 & 0.241 & 0.238 & 9 \\
\hline & BS20US & {$[0.3 * \mathrm{HN} / 0.5 * \mathrm{PFA}]_{2} / 0.3 * \mathrm{HN}$} & 1.9 & 0.048 & 0.049 & 5 \\
\hline & BS21 & {$\left[0.5^{*} \mathrm{HPP} / 0.5^{*} \mathrm{PFA}\right]_{9} / 0.5^{*} \mathrm{HPP}$} & 9.5 & 0.241 & 0.239 & 19 \\
\hline & BS21S & {$\left[0.5^{*} \mathrm{HPP} / 0.5^{*} \mathrm{PFA}\right]_{2} / 0.5^{*} \mathrm{HPP}$} & 2.5 & 0.064 & 0.069 & 5 \\
\hline & BS22 & {$\left[0.5^{*} \mathrm{HPP} / 1^{*} \mathrm{PFA}\right]_{9} / 0.5^{*} \mathrm{HPP}$} & 14 & 0.356 & 0.380 & 19 \\
\hline
\end{tabular}

Note: * indicated thickness in mil (1/1000 inch)

For the MMEI structures, their dielectric performance seemed to depend upon various material, process, and structural parameters, such as dielectric properties of constituent materials, inter-layer bonding integrity, overall thickness, total number of layers or interface, individual layer thickness, and ratio of constituent materials, etc. With the data available to date, the effects of those parameters on dielectric performance of MMEI system were assessed systematically in terms of $K$, but rather semi-quantitatively since many of the controlling parameters were not clearly separable, e.g., overall sample thickness, layer thickness, or number of layers etc. For some configurations, they were fabricated and tested for two different batches, but both were included in the systematic analyses to capture the process-induced variations. The effects of inter-layer bonding integrity on dielectric performance of multilayer structures were clearly identified, not from the current MMEI structures but from other systems studied earlier, e.g., $\mathrm{KBF} / \mathrm{PFA} / \mathrm{Kapton} \mathrm{PI} / \mathrm{PFA}$ on BN substrate ( $\sim .82 \mathrm{~mm}$ thick). The comparisons were somewhat extreme, but it was 
of interest to note that $V_{B}$ or $K$ of the structure increased by more than $38 \%$ of the BN substrate when they were heat fuse-bonded together, while there was only $10 \%$ or no increase from that of the $\mathrm{BN}$ substrate when the layers were just physically contacted. When they were not bonded, the high voltage current moved around between the interlayer space freely, found weak spots, and broke/penetrate, i.e., failed at lower voltage. But, if the layers were bonded well, the current had no choice but forced to go through the same location on the next layer as the initial penetration of BN substrate regardless of weak spots on the next layer, i.e., needing higher voltage.

Initially, it was perceived from some early data that dielectric performance of MMEI structures made of PI and PFA was mostly governed by PI layers. However, the increase rate in $V_{B}$ of a selected MMEI configuration as a function of overall thickness, but by only increasing thickness of PFA layers from 0.5 mil to 1 mil to 2 mil (i.e., BS20S vs. BS20SR vs. BS20ST in Table 1) was higher than that of PFA film itself, Figure 4, which suggested that PFA layers also contributed positively to the overall dielectric performance of MMEI structure. More quantitative analyses on the contribution of each constituent materials to the overall MMEI performance are discussed later. As for the bond layer, PFA performed slightly better than PET by comparing BS17N vs. BS23 or BS19 vs. BS23N based on their layup configurations with the same KBF contribution and overall thickness as also expected from dielectric performance of virgin material, $10.7 \pm 0.2 \mathrm{kV}$ for PFA vs. $8.0 \pm 0.5 \mathrm{kV}$ for PET in $V_{B}$ of $2 \mathrm{mil} / 0.052 \mathrm{~mm}$ thick films. It should be also noted that PFA film lost about $12 \%$ in dielectric strength when exposed to $350{ }^{\circ} \mathrm{C}$ while most PI films regardless of brand or thickness didn’t lose their dialectic strength but gained slightly up to $13 \%$.

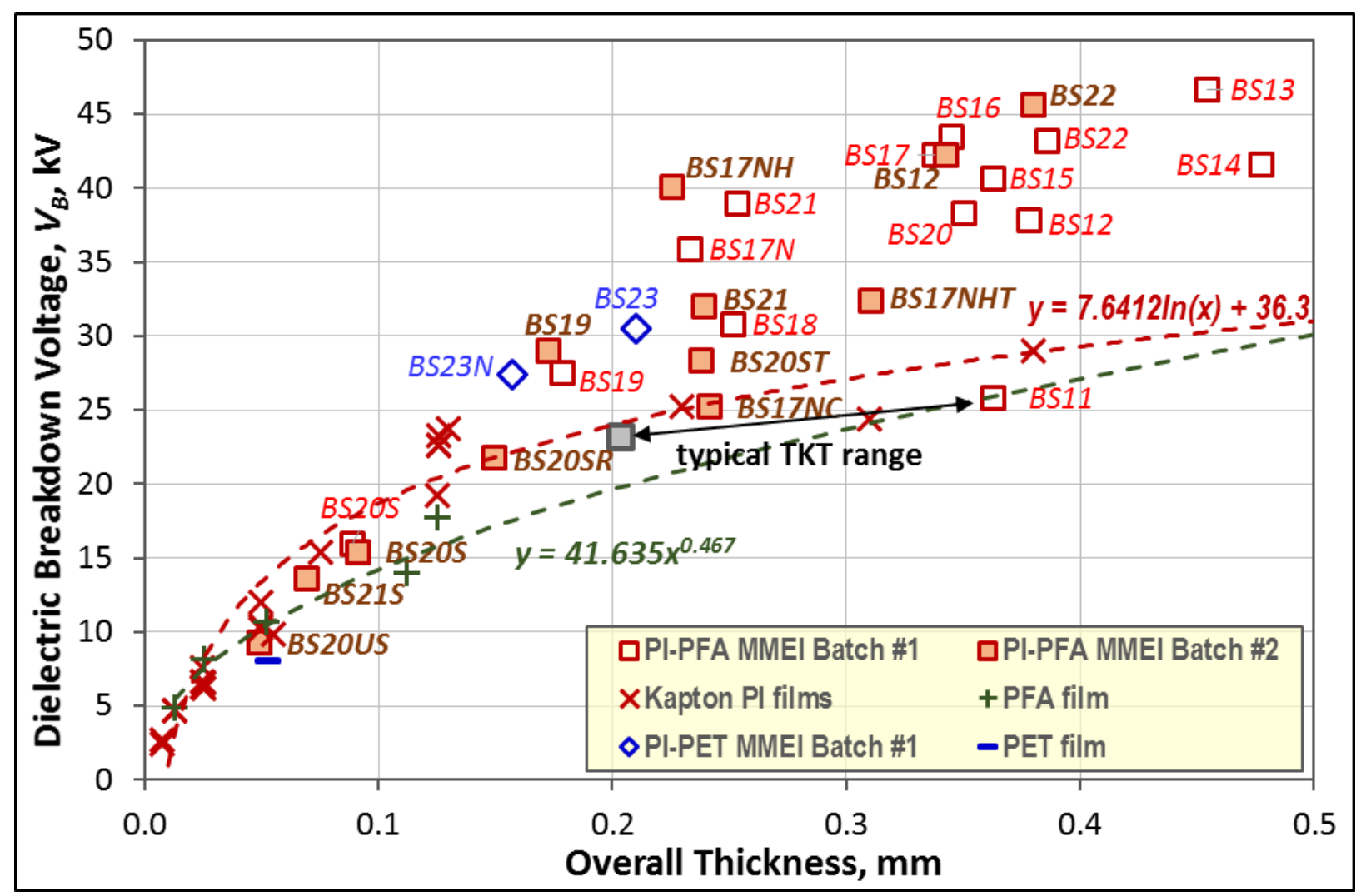

Figure 4. Dielectric breakdown voltage of various MMEI structures compared to those of the SOA insulation films.

The critical structural parameters of interest that might control the overall dielectric performance of the MMEI structures included individual layer thickness, total accumulated thicknesses of constituent materials, overall accumulated thickness ratio of constituent materials, and total number of layers or interfaces in addition to total thickness. It should be noted that in the following analyses, dielectric strength, $K$, of MMEI structures instead of $V_{B}$ was used for comparison in order to minimize the errors resulting from thickness differences in each selected thickness ranges even though $K$ was still thickness-dependent. Figure 5 shows the effects of individual layer thickness of PI and PFA, respectively, on the overall $K$ of MMEI structures after selecting some comparable data in terms of overall thickness and total thickness of the constituent material. For both PI and PFA, $K$ of MMEI increased with decreasing

American Institute of Aeronautics and Astronautics 
layer thickness, but leveled off at $\sim 0.05 \mathrm{~mm}$ based on the best-fit $2^{\text {nd }}$ order polynomial trendlines. The trends were consistent with the overall behavior of MMEI structures illustrated in Figure 4 in that most MMEI structures showed considerably higher $V_{B}$ than PI alone films but only if the overall thickness was greater than $\sim 0.15 \mathrm{~mm}$. That is, thinner layers below the limit were no longer effective for the synergistic effects of MMEI structures on the improved dielectric performance. On the other hand, these data reconfirmed that both PI and PFA contributed to the overall $V_{B}$ of MMEI structures. Figure 6 was another plot showing the similar effects of PI layer thickness on $K$ of MMEI structures at various ranges of overall thickness, but regardless of the total PI thickness. Based on the analyses so far, it was suggested that individual layers thinner than $\sim 0.05 \mathrm{~mm}$ of either PI or PFA did not provide benefits to MMEI structures in terms of dielectric performance. However, the effects of the layer thickness on other material types including ceramic or inorganic, e.g., BN, and also on other multifunctionalities, e.g., mechanical durability, EMI shielding, or corona resistance, etc. will be evaluated separately.
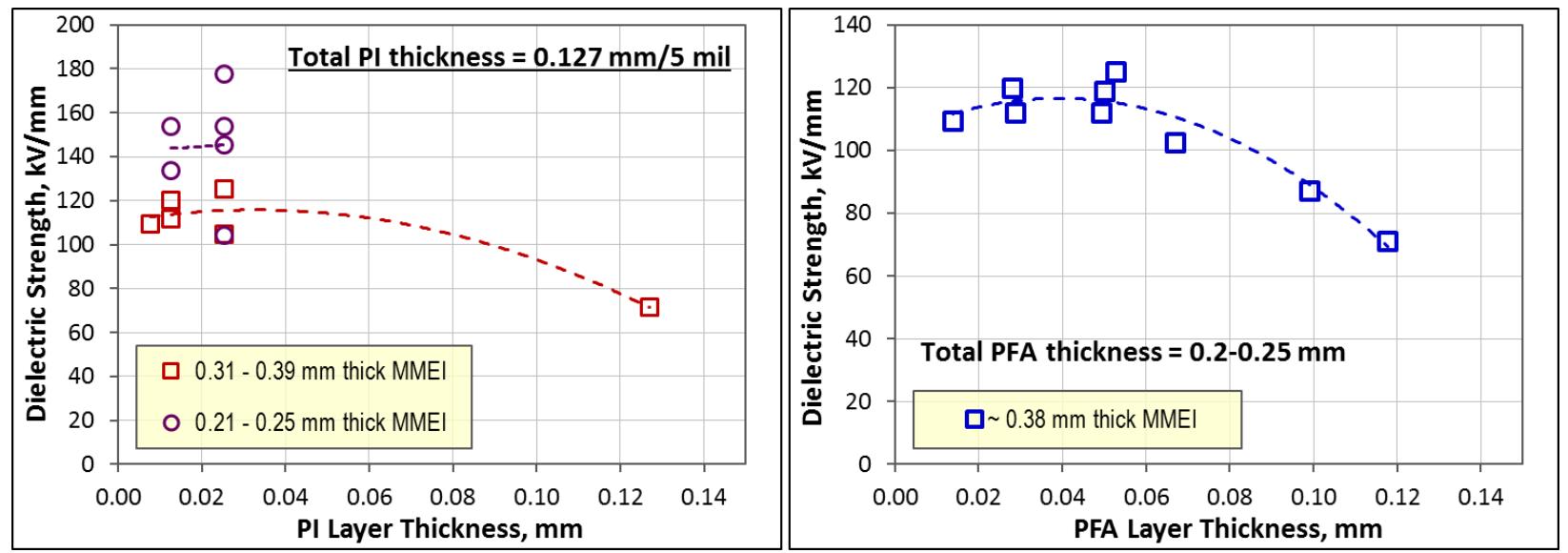

Figure 5. Effects of layer thickness on dielectric strength of MMEI structures.

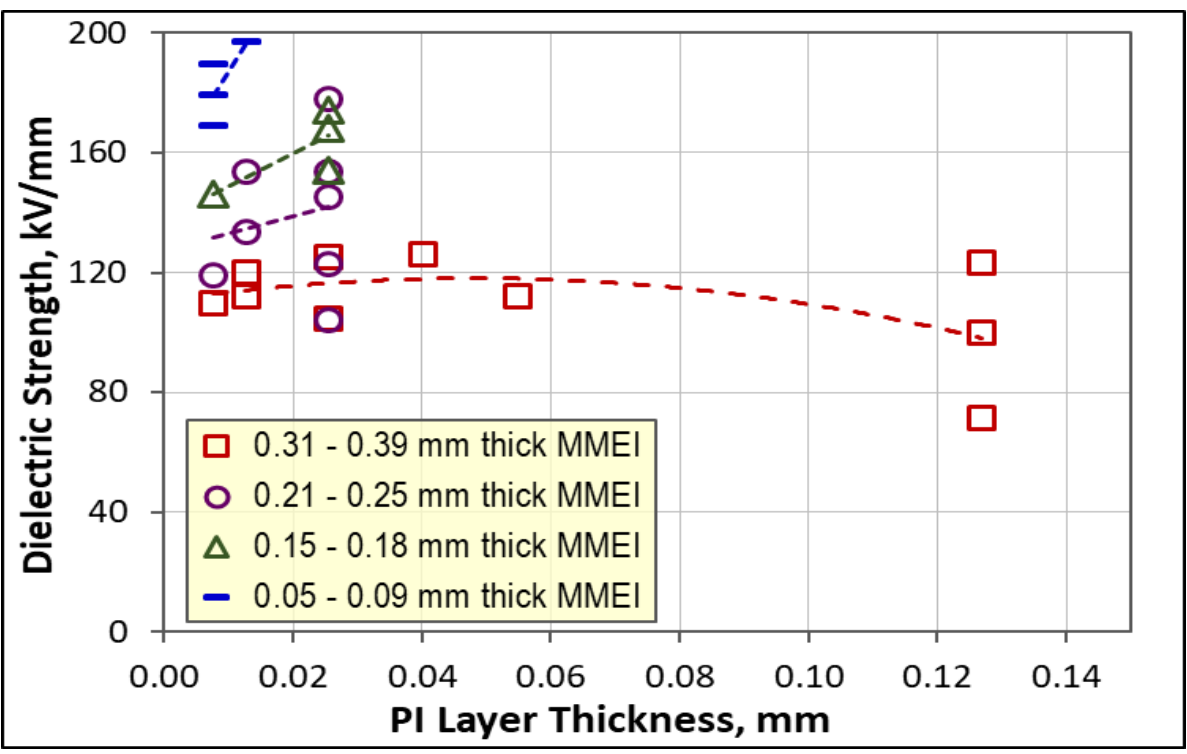

Figure 6. Dielectric strength of MMEI structures in terms of PI layer thickness.

The effects of total thickness of the constituent materials, PI and Bond layer (BL) either PFA or PET, on $K$ of MMEI structures were analyzed in Figure 7 including simple-fit linear trendlines. For the most overall thickness ranges except 0.05 to $0.09 \mathrm{~mm}, K$ of MMEI structures increased with increasing total accumulated thickness of PI layers. However, it decreased with increasing total accumulated thickness of bond layers, either PFA or PET, regardless of overall MMEI thickness. Thus, adding more layers or thicker layers of PI while decreasing bond layer thickness improves $K$ of MMEI structures. This behavior was also revealed by $K$ vs. overall PI/BL ratio plot, Figure 8 , with simple-fit linear trendlines. As expected from their intrinsic dielectric properties, the overall $K$ of MMEI

American Institute of Aeronautics and Astronautics 
structures increased with increasing the overall PL/BL ratio regardless of their overall thickness. On the other word, the contribution of PI layers on the overall $K$ of MMEI structures was greater than that of bond layers of PFA or PET.
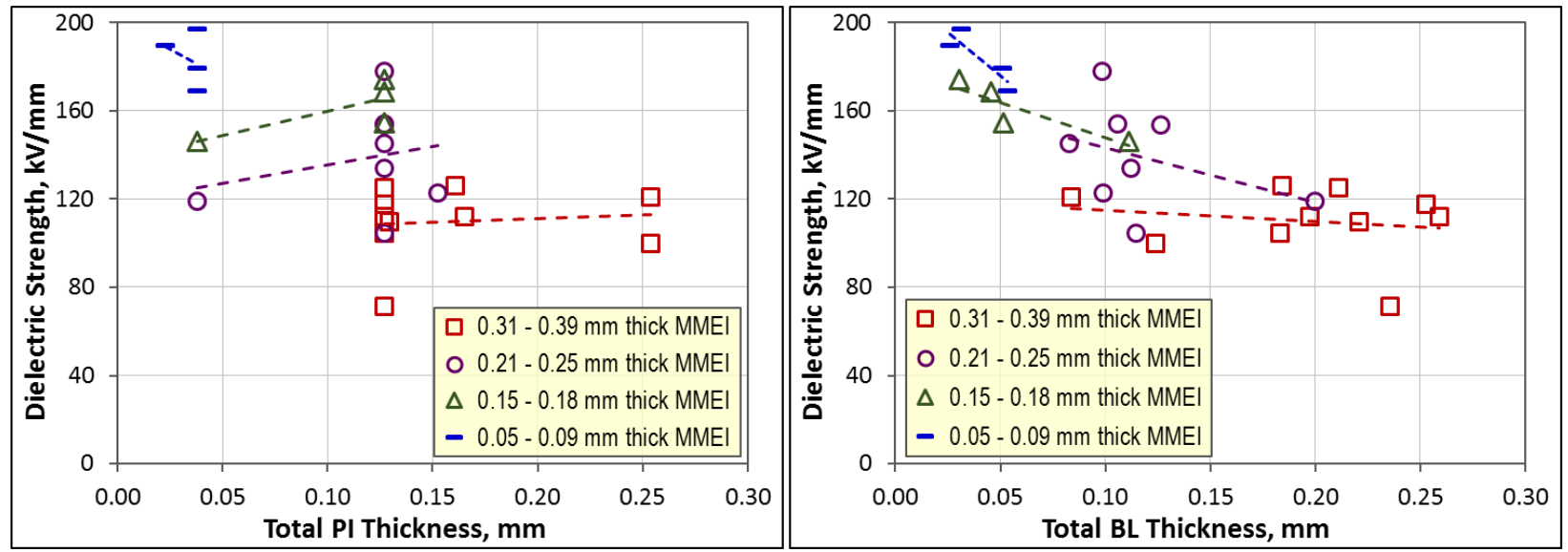

Figure 7. Effects of total constituent material thickness on dielectric strength of MMEI structures.

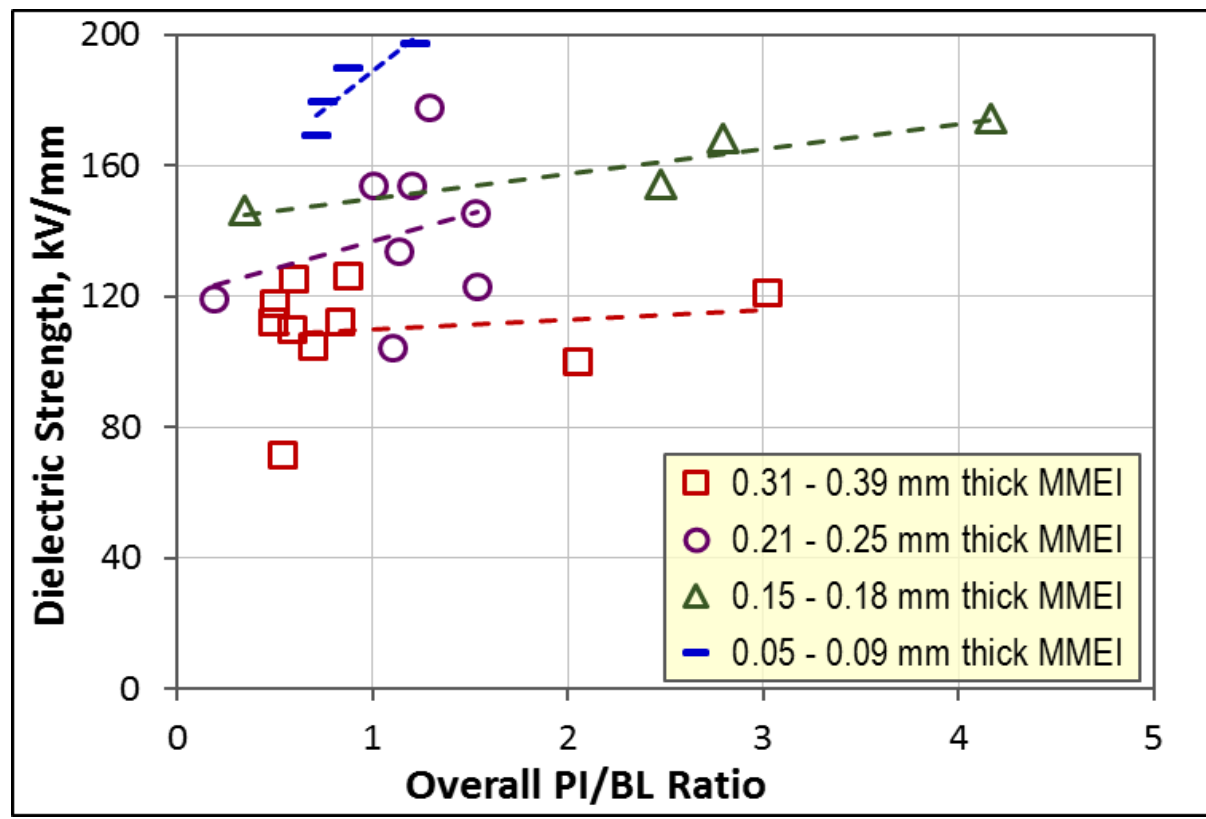

Figure 8. Dielectric strength of MMEI structures in terms of overall PI/BL ratio.

Based on the linear trendlines, $K$ of MMEI structures increased slightly with increasing number of interface or total number of layers, but only for thicker MMEI structures than $\sim 0.21 \mathrm{~mm}$ as illustrated in Figure 9 . The trend was opposite when the overall thickness was less than $0.15 \mathrm{~mm}$ which was somewhat related to the overall MMEI behavior ascertained in Figure 4. It was indicated that there was no impact of the MMEI structures on dielectric performance if their overall thickness was less than $0.15 \mathrm{~mm}$ regardless of their material, structural, or process-related variables investigated to date in this study. The results of the above semi-quantities analyses in determining influences of each structural/configurational parameters on dielectric performance of MMEI structures will be systematically applied to design future, more efficient MMEI structures with maximized $V_{B}$ or $K$.

American Institute of Aeronautics and Astronautics 


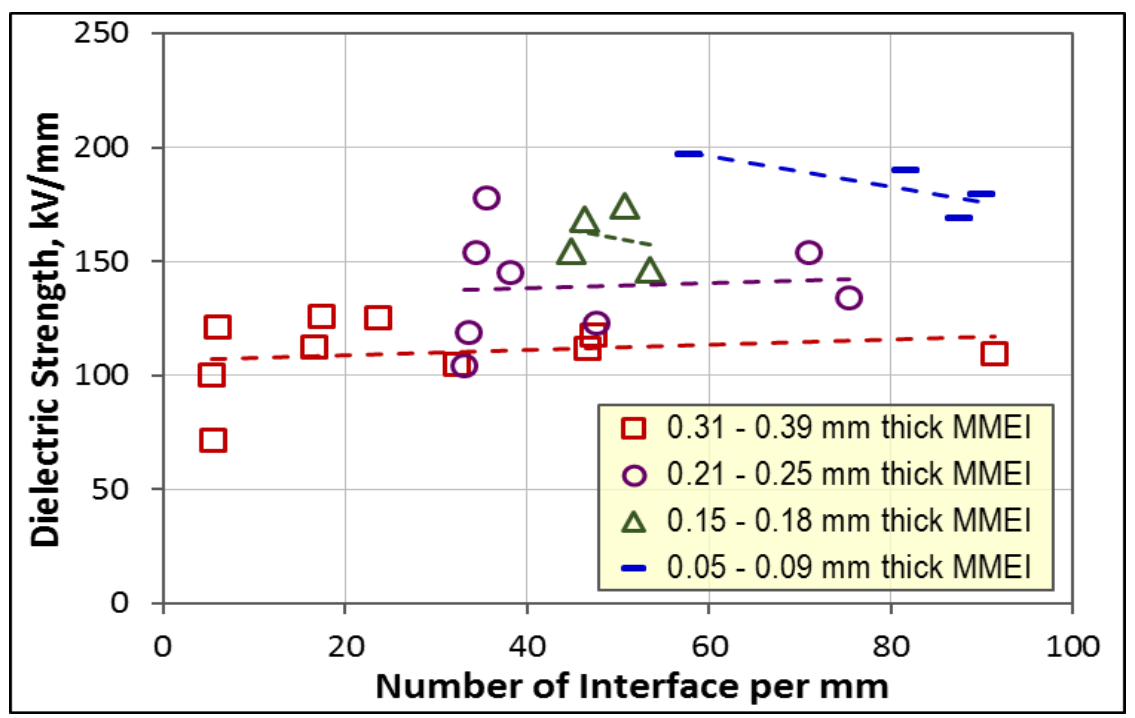

Figure 9. Dielectric strength of MMEI structures in terms of the number of interface per $\mathbf{m m}$.

After dielectric strength testing, dielectric breakdown failure mode of all samples were systematically examined under an optical microscope. Figure 11 through Figure 12 illustrated the typical failure modes of PFA alone films, PI alone films, and representative MMEI structures, respectively. Note that sizes of the scale bars were varied among micrographs due to varying magnifications in order to cover the entire damage zones as much as possible with reasonable resolution. Failure mode of PFA involved melting and through-hole perforation (THP) with minor charring around the hole for all thicknesses studied consistently. The hole size seemed to increase with increasing thickness from 50 to $100 \mu \mathrm{m}$ dia. for $0.013 \mathrm{~mm}$ thick to $>200 \mu \mathrm{m}$ dia. for $0.025 \mathrm{~mm}$ thick, but there were no significant changes with further increases in thickness. Typical failure mode of PET resembled those of PFA for the thicknesses studied. In the case of PI films, the failure mode changed from THP to partial perforation (PP) at about $0.05 \mathrm{~mm}$ thickness except those modified PI, e.g., TCPI or PI shrink tape. Up to $0.013 \mathrm{~mm}$ thick, PI failed by melting and charring followed by THP, but at thickness of $0.025 \mathrm{~mm}$, microcracks appeared before THP. At the thickness above $0.05 \mathrm{~mm}$, they were failed by localized charring and PP after extensive cracking and cavitation, especially around the outer diameter of the $1 / 4$ inch dia. electrode. The area of cracking and cavitation was identified as damage zone as shown in Figure 11 (d), and their width, DZW, was measured consistently as a function of overall thickness. Typical failure modes of MMEI structures were similar to those of PI films except debonding or inter-layer separations which were unique in MMEI structures due to their multilayer configurations. Similar to PI or PFA films, thinner MMEI structures, e.g., $\sim 0.05 \mathrm{~mm}$ thick BS20US or $\sim 0.07 \mathrm{~mm}$ thick BS21S, failed by THP, but in some cases, much thicker structures, e.g., $0.24 \mathrm{~mm}$ thick BS20ST were also failed by THP, probably as a result of less amount and thinner layers of PI in the structure. Samples failed by THP normally showed lower $V_{B}$ or $K$. Otherwise, most MMEI structures involved microcracking or cracking, cavitation, debonding, melting, charring, and PP in their failure mode, but the ultimate breakdown occurred via the localized charring and PP as the final breakdown path. As can be seen from the micrographs, the size of DZW and the final breakdown path varied with different insulation materials or MMEI configurations, mostly depending on the overall sample thickness.
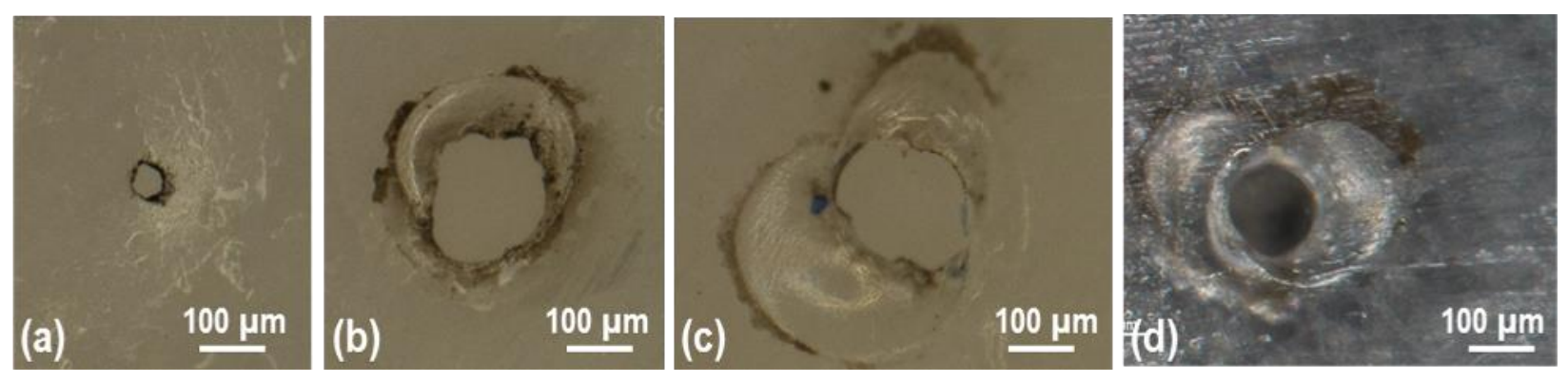

Figure 10. Typical dielectric breakdown failure modes of PFA films: (a) 0.013 mm th.; melt, THP, (b) 0.025 mm th.; melt, char, THP, (c) 0.05 mm th.; melt, char, THP and (d) 0.125 mm th.; melt, char, PP.

American Institute of Aeronautics and Astronautics 

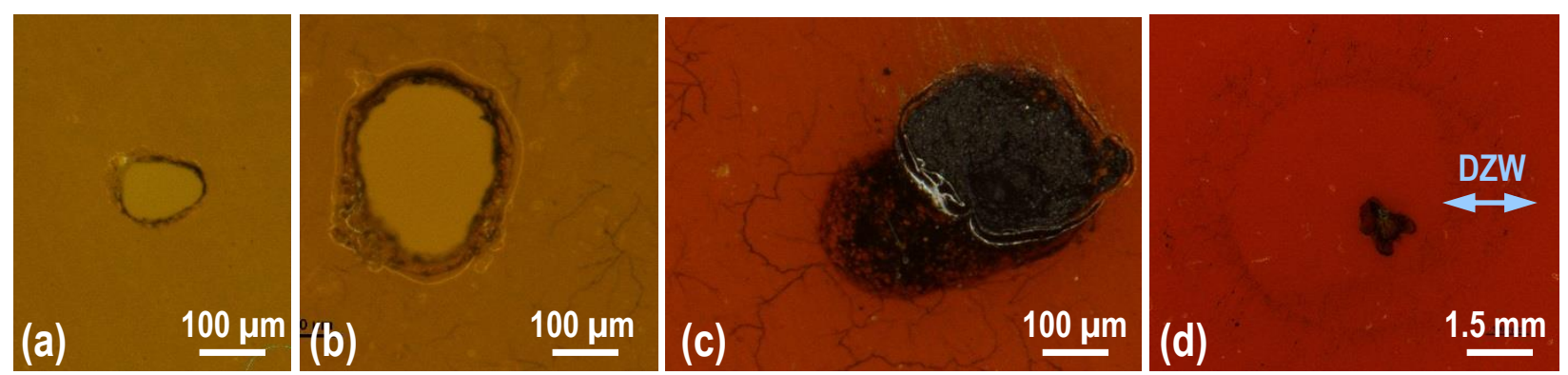

Figure 11. Typical dielectric breakdown failure modes of Kapton PI films: (a) 0.013 mm th. HPP-ST; THP, (b) $0.025 \mathrm{~mm}$ th. HN; crack, THP, (c) $0.05 \mathrm{~mm}$ th. KBF; crack, cavitation, melt, char, PP and (d) $0.126 \mathrm{~mm}$ th. HN; extensive crack-cavitation DZ, melt, char, PP. Note that DZW in (d) defined width of damage band.
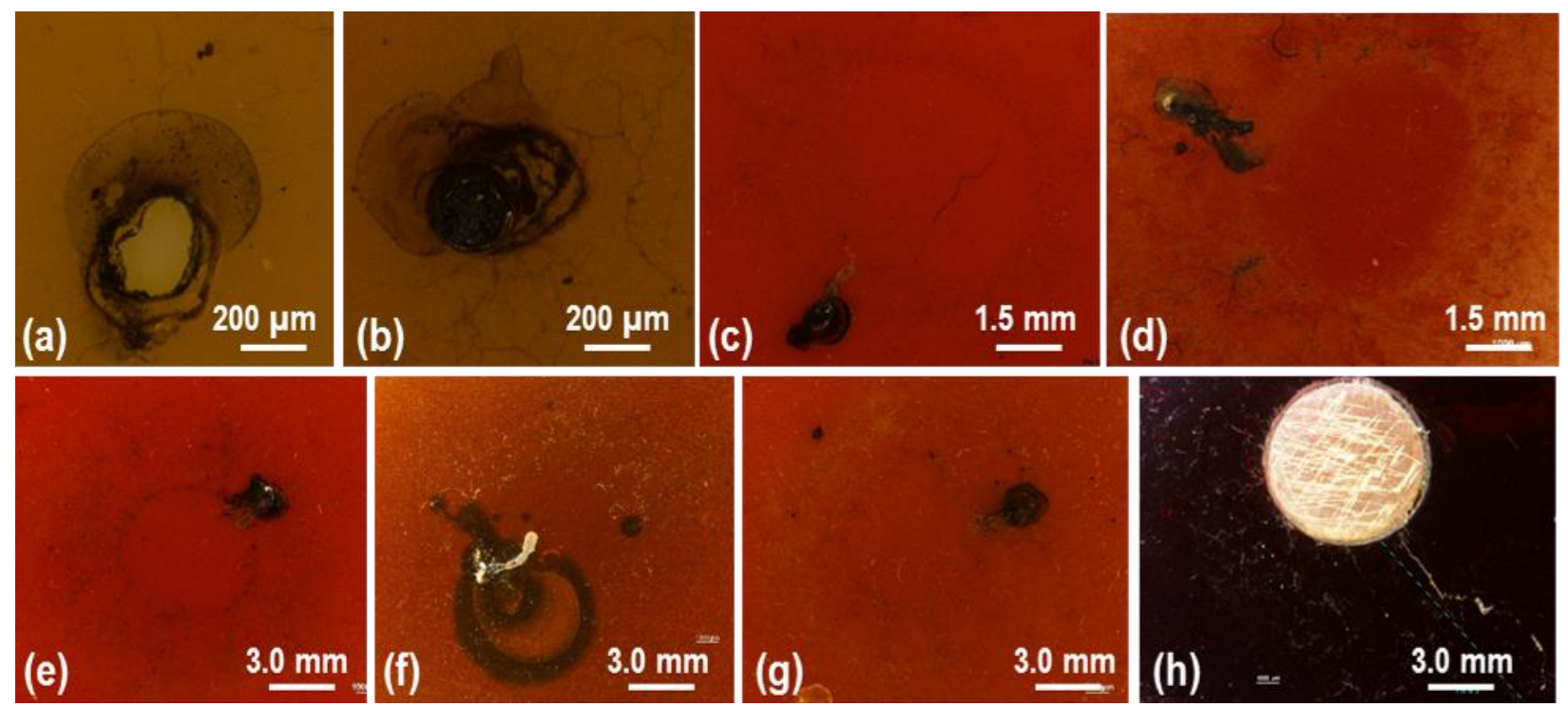

Figure 12. Typical dielectric breakdown failure modes of MMEI structures: (a) $0.05 \mathrm{~mm}$ th. BS20US showing crack, debond, melt, char, THP, (b) $0.125 \mathrm{~mm}$ th. BS20SR, (c) $0.173 \mathrm{~mm}$ th. BS19, (d) $0.31 \mathrm{~mm}$ th. BS17NHT, (e) $0.2235 \mathrm{~mm}$ th. BS17NH, (f) $0.345 \mathrm{~mm}$ th. BS16, (g) $0.38 \mathrm{~mm}$ th. BS22, and (h) $0.455 \mathrm{~mm}$ th. BS13; (b) thru (h) all showing crack, cavitation, debond, melt, char, and PP.

The sequence of damage evolution in MMEI structures as a function of voltage was experimentally determined, Figure 13. While testing a few MMEI structures, e.g.., BS17N, BS20, BS22, or BS23, for $V_{B}$ or $K$, the samples were stopped at certain voltage levels, examined for any damages under microscope, and resumed to breakdown. Typical damage evolution sequence of the $0.233 \mathrm{~mm}$ thick BS17N as an example was initial micro-cracking and cavitation at about $22 \mathrm{kV}$, presumably in Kapton PI layers, while the sample was still insulating, followed by the extensive crack propagation, cavitation, localized debonding, melting, charring, and PP causing dielectric breakdown of the sample at about $36 \mathrm{kV}$.

From the extensive dielectric breakdown failure mode analyses of all the materials and structures, it was suggested that, for a given overall thickness, the failure mode seemed to change from more catastrophic mode involving cracking, cavitation, charring, PP or THP in single polymer insulation films to more gradual or progressive mode involving microcracking, cavitation, melting, channeling, debonding, interfacial swelling, charring and PP in the new MMEI structures. In general, dielectric breakdown failure of MMEI structures proceeded with a progressive damage evolution involving more damage types/events and larger damage zones, which suggested that more energy was involved in the breakdown process, thus resulted in the higher dielectric strength. Figure 14 showed direct correlation between $K$ and DZW of MMEI structures for various overall thickness ranges. It was evident that the higher $\mathrm{K}$ was, the larger DZW was or vice versa regardless of overall thickness ranges of MMEI structures.

American Institute of Aeronautics and Astronautics 


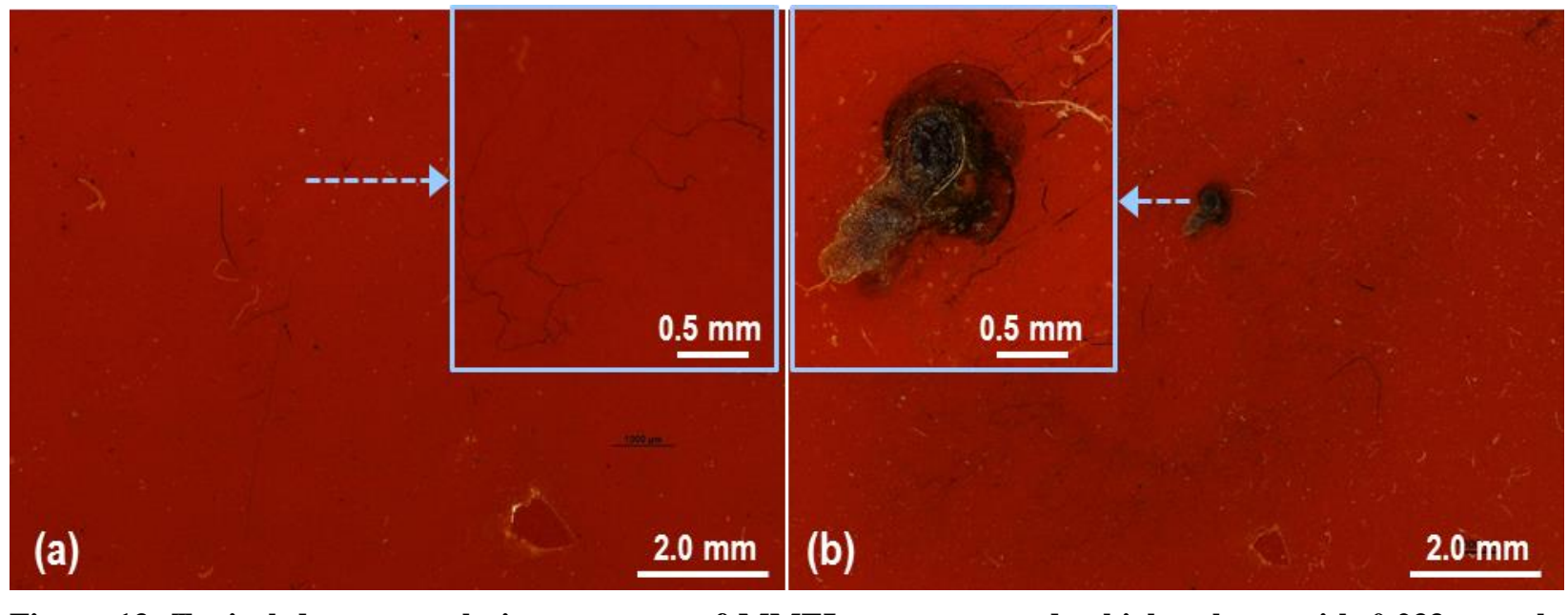

Figure 13. Typical damage evolution sequence of MMEI structures under high voltage with $0.233 \mathrm{~mm}$ th. BS17N: (a) micro-cracking, cavitation, presumably in Kapton PI layers at $22 \mathrm{kV}$, (b) extensive crack propagation, cavitation, localized debonding, melting, charring, and PP at dielectric breakdown at $36 \mathrm{kV}$.

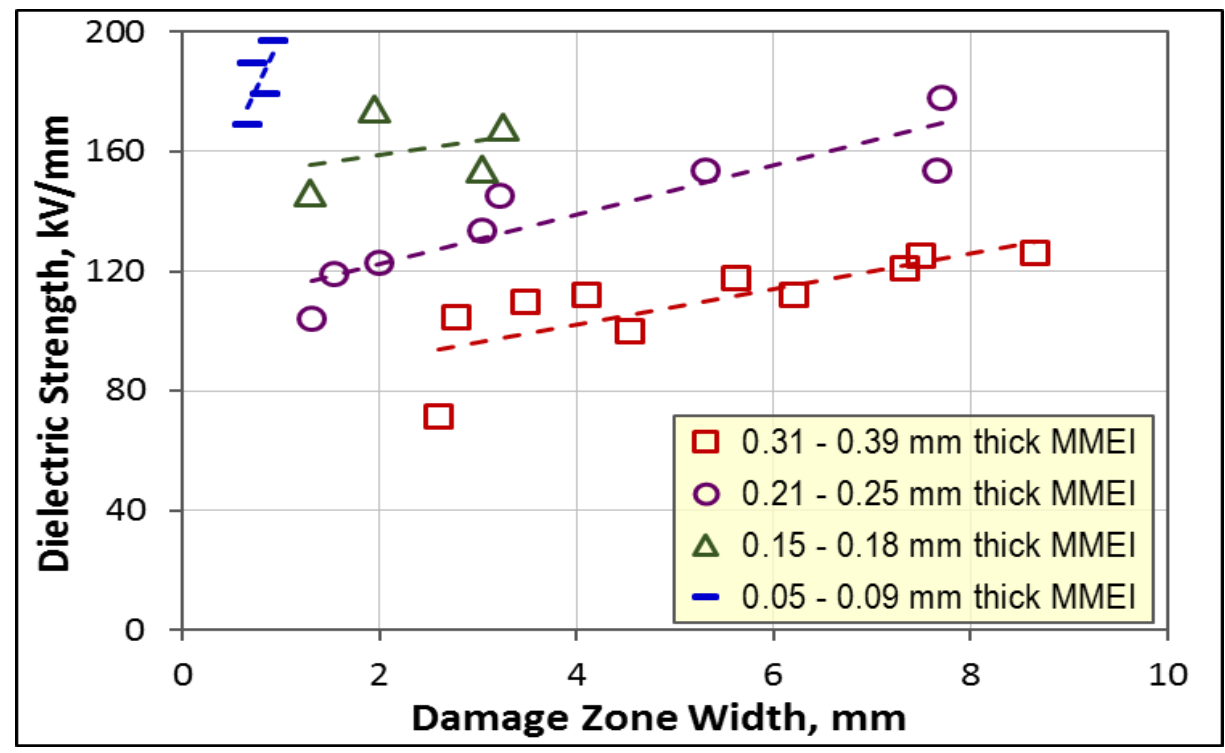

Figure 14. Dielectric strength of MMEI structures in terms of damage zone width.

Since several different types of PI materials as listed in the "Materials" section were considered for MMEI structures for possible multifunctionality in this study, the effects of PI material modifications on $K$ or $V_{B}$ (figures listed on top of each bar) were investigated in either single-material film or MMEI structures as shown in Figure 15. For the former, some modified PI such as corrosion resistant PI (CRC), TCPI, and ECPI were compared to the typical Kapton PI, KBF or $\mathrm{HN}$ while the latter compared $\mathrm{CRC}$ to $\mathrm{KBF}$ or $\mathrm{HN}$ by using BS17N configuration, and also elaborated the effects of adding extra PTFE layer to the BS17NH. Based on compositional analysis by SEM/EDS, ECPI contained $\mathrm{S}$ and $\mathrm{P}$ in addition to $\mathrm{C}$ and $\mathrm{O}$ from its molecular backbone while TCPI showed $\mathrm{Al}_{\text {as }}$ possible $\mathrm{Al}_{2} \mathrm{O}_{3}$. As well-known in literature, most modifications, typically via addition of fillers or additives, decreased $K$ in either PI alone film or MMEI structures since the fillers or additives, especially their interfaces with matrix material, acted as defects. Compared to $K$ of KBF, TCPI lost about $28 \%$ while ECPI showed only about $4 \%$. TCPI was considered for thermal management and ECPI as EMI shielding, but with their poor dielectric strength, other SOA heat dissipation film eGRAF which was also electrically conductive cooed be consider for both thermal management and EMI shielding. As a single-material film, CRC only lost less than $7 \%$ compared to $\mathrm{HN}$, but more than $40 \%$ when incorporated in BS17N MMEI configuration, i.e., BS17NC vs. BS17NH, thus a care must be taken when using the CRC PI for designing MMEI structures with improved corona resistance. Significant drop in $V_{B}$ and $K$ of BS17NHT, which added extra layer of 2 mil PTFE on top of BS17NH, compared to those of BS17NH was unexpected and not

American Institute of Aeronautics and Astronautics 
fully explained at the moment except a potential cause of possibly weaker bonding between PFA and PTFE. It was of interest to note that difference in DZW between those two structures was significant, $2.8 \mathrm{vs} .7 .7 \mathrm{~mm}$, which suggested that BS17NHT underwent more localized/concentrated failure path through a weak spot.
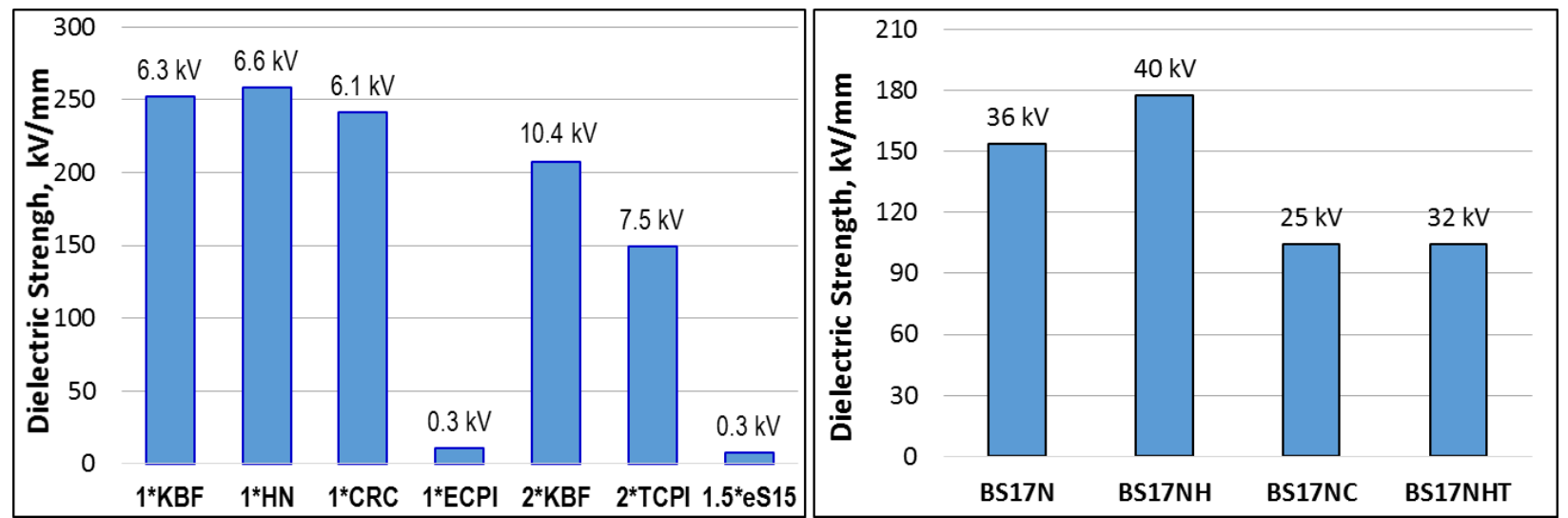

Figure 15. Effects of PI material modifications on dielectric strength of Kapton PI (left) and MMEI structures (right). $K$ of eGRAFT SS1500 was also compared to that of ECPI.

Based on experimental observations and property analyses to date, it can be postulated that the significant property improvement of the new MMEI system was achieved by combinations of various responsible mechanisms including (i) molecular rearrangement-induced changes in capacitance or conductance, (ii) formation of more torturous path for electron move from multilayered structures, (iii) less or smaller void formation by heat fuse-bonding between layers resulting in less partial discharge, and (iv) increased space charge formation/storage capacity at interfaces resulting in lower voltage potentials. Efforts will be continued to develop other potential mechanisms and validate them experimentally.

\section{B. Design and Process Optimizations}

Even though the performance improvement of the new MMEI structures was already significant as they are, it is strongly anticipated that their performance can be further improved when their design-structural configurations, insulation material types, and process-fabrication conditions are optimized. Lately, efforts were focused to increase their breakdown voltages while further decreasing their overall thickness as thin as possible, but the latest data indicated that there was a physical limitation of the structures in terms of their overall thicknesses which was about $0.15 \mathrm{~mm}$ for the studied materials including Kapton PI, PFA, or PET. On the other hand, improvement of processing conditions/procedures, e.g., more accurate and uniform control of fuse-bonding temperature, compression loading at processing temperature, and cleanliness, granted additional increase of dielectric breakdown strength in various MMEI structures including BS12, BS19, and BS22 in batch \#2. However, dielectric strength of thinner structures below the limitation was less affected by processing conditions, e.g., BS20S. In any case, the design and processing optimizations followed by standardization have to be completed to maximize performance and consistency of the new MMEI system. As suggested earlier, the MMEI structures can incorporate multifunctionalities by the nature of their design capabilities, such as Corona PD resistance, EMI shielding, mechanical durability, or thermal management as depicted by an example in Figure 16. Experimental evaluations of such multifunctionalities in terms of layer configurations, material sections, process optimizations, and performance validations are currently under way. Synergistic effects of various functional layers and interfaces on the overall performance and durability of MMEI structures will be assessed by in-service environmental simulation testing. It should be also noted that the MMEI structures with thinner and more layers can be much more ductile and durable than those with thicker or less layers or the SOA TKT system in reference to previous investigation on the brittle-to-ductile transition in micro-multilayer composites (Ref. [17]). Eventually, scale-up design and manufacturing optimizations will be followed and implemented per application. Potential manufacturing options for the new MMEI system include hot-melt calendaring, compression-molding, stamping, laminating, extrusion, autoclaving with vacuum-bagging, depositing, or 3D printing additive manufacturing, and so forth, depending on application specifics.

American Institute of Aeronautics and Astronautics 


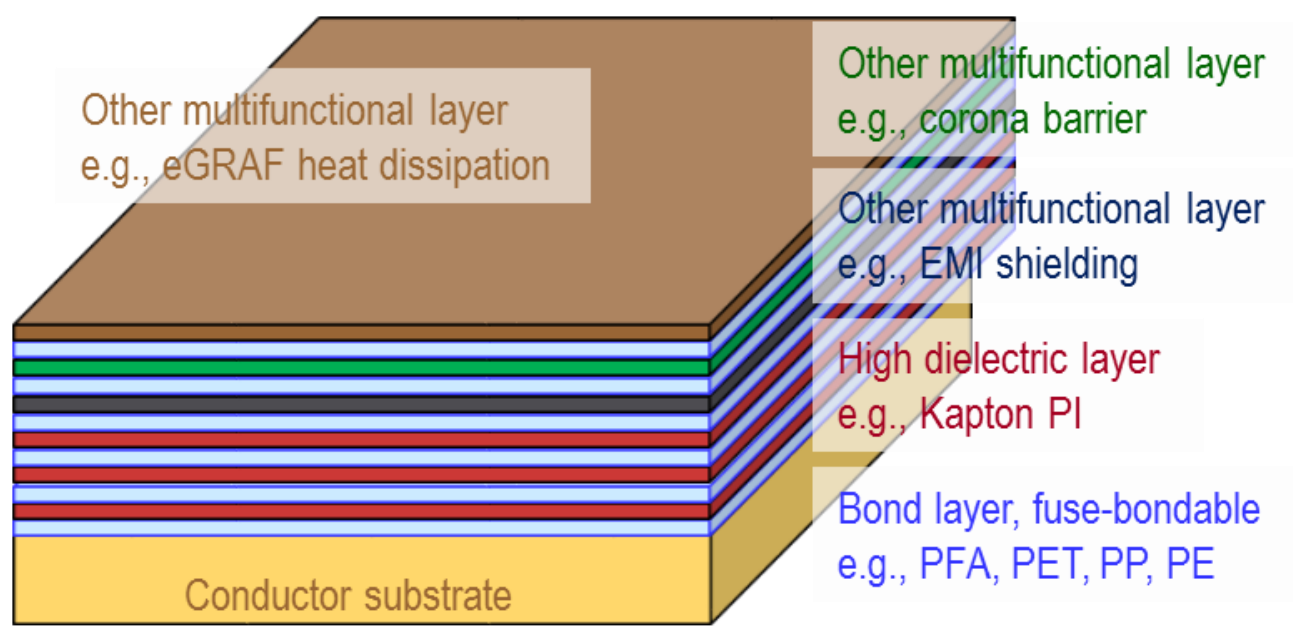

Figure 16. Typical example of a future MMEI Design.

\section{Commercial Benefit/Applicability}

The new, high voltage capable, but also lightweight, durable, and multifunctional insulation systems, namely MMEI will warrant major commercial benefits in various applications and markets, potentially current market of the low power $(<1 \mathrm{MW})$ electric hybrid aircrafts and future market of the intermediate power $(>1-5 \mathrm{MW})$ or high power (up to $20 \mathrm{MW}$ ) electric aircrafts as well as non-aerospace applications, such as high voltage electronic parts and components, printed circuit board, and so on. Attempt will be made to contact various industries including aircraft manufacturers, suppliers, or high voltage electrical component manufacturers to assess feasibility of implementing the new system using the variety of processing techniques. On the other hand, performances of the scaled up MMEI systems are being evaluated more systematically in order to validate their practicality and applicability via direct comparison with those of the SOA commercial high voltage power transmission systems as follows.

\section{High Voltage Power Cable}

Under the auspices of NASA-GRC, a new HV power pod cable was uniquely designed and fabricated by GORE (W. L. GORE \& ASSOCIATES, INC., Landenberg, PA) for this study. The pod cable was designed to carry total 0.25 megawatt at $15 \mathrm{kV}$ (but targeting to $40 \mathrm{kV}$ ), and applicable to $-80{ }^{\circ} \mathrm{C}$ to $>260{ }^{\circ} \mathrm{C}$ service temperature. As illustrated in Figure 17, it consisted of six identical conductor pods insulated by the GORE's proprietary PTFE-PTFE composite and arranged horizontally by a corona resistant PTFE jacket. From GORE's standard cable performance testing, the main PTFE composite insulation without the PTFE jacket (RED color) showed $V_{B}$ of $\sim 39 \mathrm{kV}$, but when the PTFE jacket was added, it dropped to $\sim 29 \mathrm{kV}$. It might be caused by the lamination process, but the actual root cause of the reduced $V_{B}$ after jacket lamination was not identified at the moment. The cable jacket did not have any defects or signs of damage.
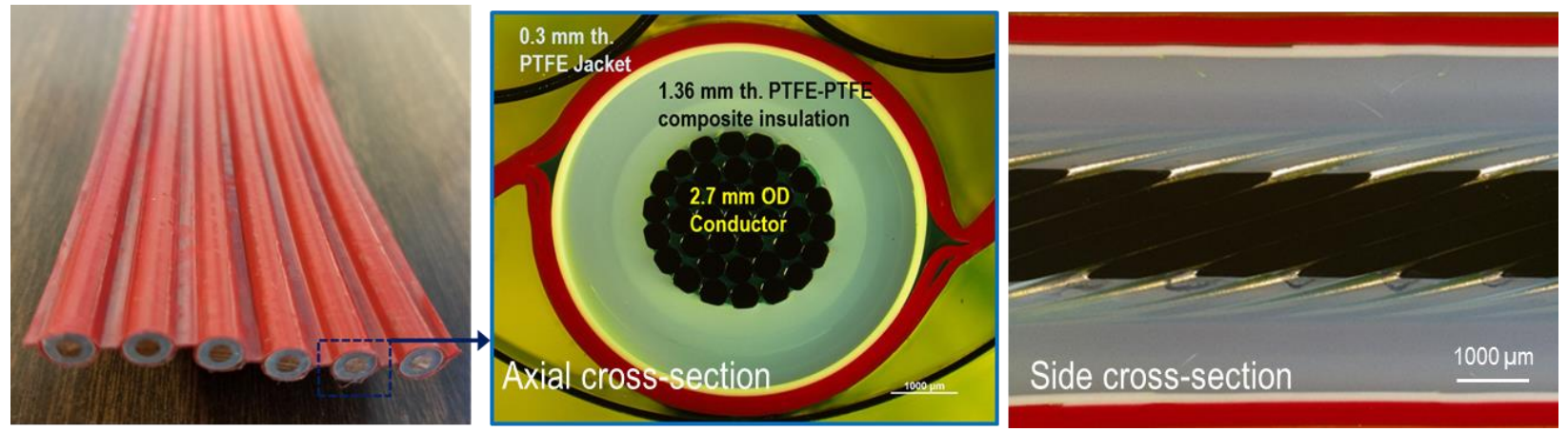

Figure 17. GORE high voltage pod cable.

Attempt was also successfully made to determine $V_{B}$ of the GORE cable directly using the dielectric strength test equipment at GRC, Figure 3. A test method to evaluate such cable structures was developed as a primary performance assessment tool. The test method was optimized after examining various test specimen configurations including as-

American Institute of Aeronautics and Astronautics 
is straight, straight with a cut-off on one side, stripped and bent conductor wrapped with aluminum foil, and bend configuration with a cut-off on bent side, and also based on their failure modes as summarized in Figure 18. The asis straight specimen was tested between the two $1 / 4$ " dia. electrodes directly without direct contact to conductor wire while specimens of all other configurations made direct contact between the conductor wire and the bottom electrode during testing. Based on consistency, reproducibility, and failure modes, the bend configuration was selected and optimized for the cable evaluation. Most failure involved THP, not always directly under but near the electrode, and in some cases, melting, debonding, and charring. With the optimized bend configuration, a commercial HV hookup wire (Belden Style 3212 rated for $600 \mathrm{~V}, 150^{\circ} \mathrm{C}$ ) with silicone rubber insulation and a separator made of two polymer films, e.g., PET and Polyoxymethylene (POM) was also evaluated for comparison. Key findings from this effort included; (i) the optimized bend configuration of the GORE pot cable produced more reliable and reproducible $V_{B}$, $30.2 \pm 1.7 \mathrm{kV}$, which was consistent with the GORE data, (ii) $V_{B}$ of the main PTFE composite insulation after removing jacket was $29.9 \pm 0.04 \mathrm{kV}$, which was the same as that of the as-received cable with jacket and suggested that the lamination process to add the jacket at GORE seemed to cause permanent change in the main PTFE composite insulation, (iii) $600 \mathrm{~V}$ silicone hookup wire performed exceptionally well, reached $23.9 \mathrm{kV}$ breakdown voltage, but (iv) inter-conductor dielectric breakdown testing (using the specimen configuration displayed in the third row in the second column in Figure 18) was not successful.

\begin{tabular}{|l|l|l|l|l|l|}
\hline & As-is Straight & Straight w cut-off & Stripped conductor & \multicolumn{1}{|c|}{ Optimized bend conf. } \\
\hline & & & & \\
\hline
\end{tabular}

Figure 18. Various dielectric strength test sample configurations of the GORE pod cable and their dielectric breakdown failure modes.

Efforts have been made to develop optimum design and fabrication concepts to apply the MMEI system to the GORE pod cable. The MMEI system will be applied on the same conductor wires following the same cable design and configuration of the GORE cable, thus their electrical insulation performance can be directly compared. The same blank conductor wires (AWG 10(37x0.404mm) NPC UNILAY, ES-10868703 Rev. A, Stranded copper wire without fittings) used in the GORE cable was also supplied by GORE. As illustrated in Figure 19, two options; (I) one step lamination process and (II) two-step process consisting of tape wrapping and jacketing, were considered. Initially, about $1 \mathrm{~m}$ long cables are planned for fabrication optimization and performance evaluations. The option II which could produce ideally more solid insulation was similar to the process used by GORE for their pod cable, but the option I should be much simpler and easier to carry out. Elimination of overwrap seamlines as in option II which might become weak spots in high voltage failure path due to trapped air (refer to the first failure mode of the 'Stripped conductor' in Figure 18) was another advantage of the option I. For both options, a modified BS22 MMEI configuration, which was one of the better performing MMEI structures in terms of $V_{B}$ and possibly more durable from its structure consisting of more and thinner layers, was selected, but much thinner BS17NH with high $V_{B}$ of 40 $\mathrm{kV}$ was also considered as a potential candidate. For the option II, the tape wrapping process needs to be optimized in terms of tape width and overwrap dimensions as well as handling of multiple layers, especially at the starting or ending steps. It will also require to optimize heat fuse-bonding of wrapped layers and the additional jacketing process

American Institute of Aeronautics and Astronautics 
to produce good inter-layer bonding. The option I could be executed by either a stamping or compression-molding with a custom-designed molds or a vacuum-bagging and autoclaving process.

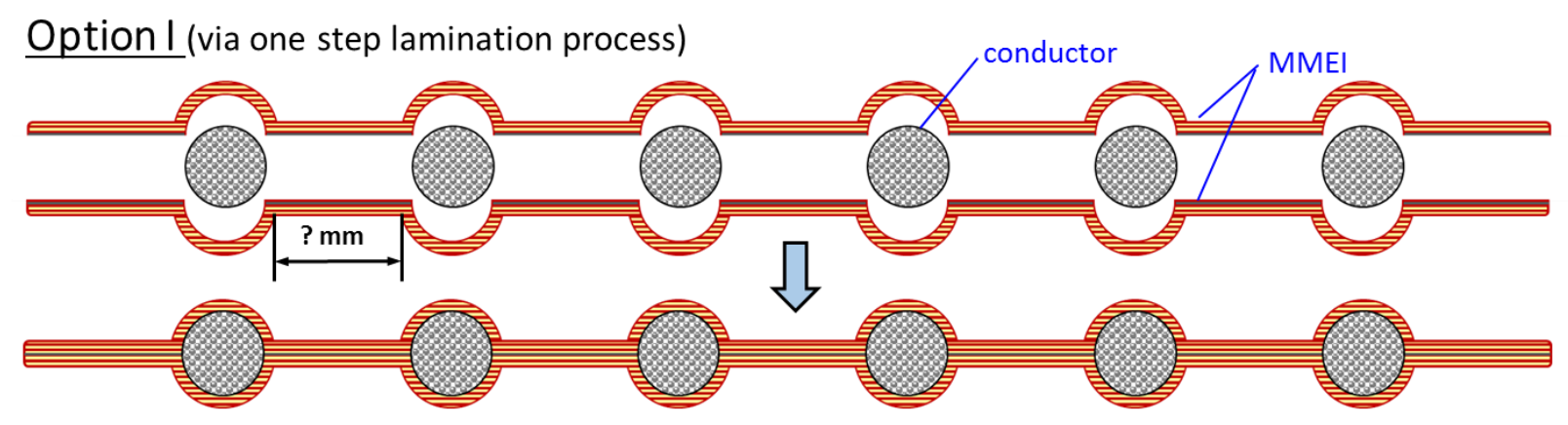

Option II (via two step process involving tape wrapping and jacketing)

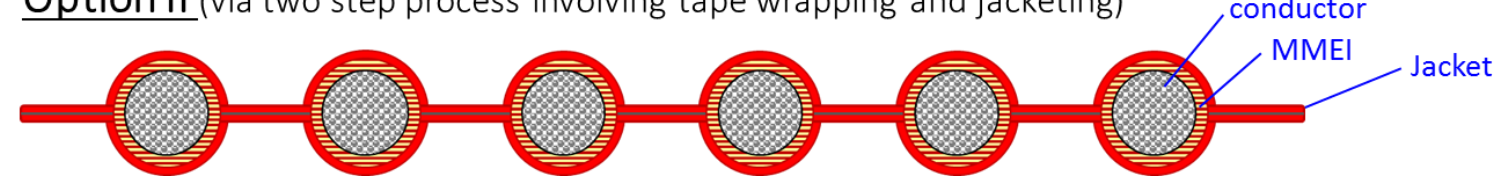

Figure 19. Two MMEI application options on GORE pod cable.

In the case of the option I, there was one unknown design parameter, so-called web width (question marked in Figure 19) or inter-conductor spacing (i.e., web width plus thickness of MMEI insulations), since $V_{B}$ or $K$ of PFA but for through-bondline which was supposed to differ from the through-the-thickness property, was not available. In order to determine the optimum inter-conductor spacing, also considered as creepage distance, that can withstand high voltage up to $40 \mathrm{kV}$ experimentally, a unique test coupon/specimen was designed as illustrated in Figure 20. As shown in the cross-section of the coupon, two pieces of 5 mil thick copper foil as a conductor were placed at the PFA bondlines in the middle of multilayer sandwich structure of Kapton PI and PFA at a predetermined gap (or interconductor spacing). Four different gap lengths, 1, 2, 3, and $5 \mathrm{~mm}$, were selected for this experiment. Each coupon with $31.8 \mathrm{~mm} \times 76.2 \mathrm{~mm}$ overall dimensions was designed to contain five test specimens for easy fabrication using the same process as the batch \#2 BS series dielectric strength test samples. Total 15 test specimens, 3 to 4 per gap length, were sectioned from three coupons. The $\mathrm{Cu}$ conductor embedded in each test specimen was $\sim 3 \mathrm{~mm}$ at the gap and its overall insulation width was $\sim 13 \mathrm{~mm}$, i.e., $\sim 5 \mathrm{~mm}$ each side which was wide enough to prevent side arcing under high voltage. Ends of the T-shaped $\mathrm{Cu}$ conductors were cleaned from any impurities and bent $90^{\circ}$ which then contacted to both electrodes of the dielectric strength tester. The gap lengths were measured as the closest between the $\mathrm{Cu}$ conductor tips more accurately using an $\mathrm{OM}$.

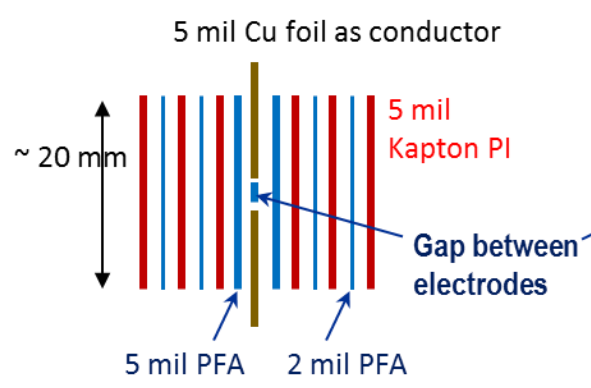

(Cross-sectional View)

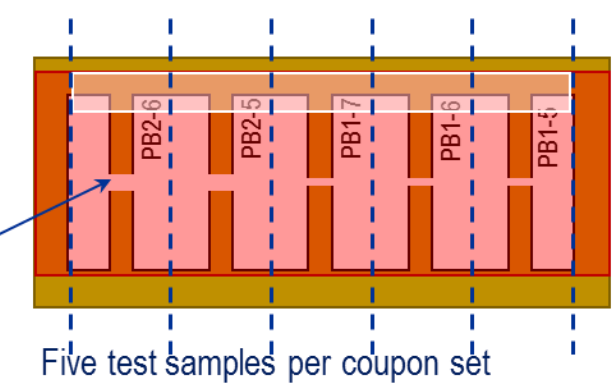

(Top View)

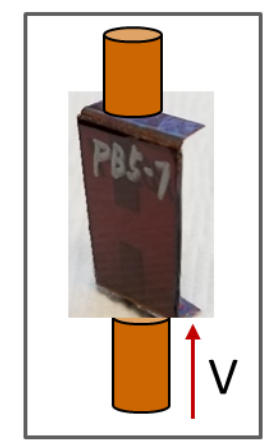

Dielectric strength testing

Design of Test Coupons/Samples

Figure 20. Experimental approach to determine inter-conductor spacing or creepage distance. 
Figure 21 shows the typical dielectric breakdown failure mode from a $1 \mathrm{~mm}$ gap specimen via both front and crosssectional view at the yellow dashed line. The sectioned specimen was mount with an epoxy and metallurgical polished for more accurate microscopic examination in order to identify exact failure path, whether it was through the bondline or not. Typical damage types observed from various specimens included cracking of PI, PFA-PI interface debonding, cavitation, melting and charring of both layers, and perforation. The damage types occurred per specimen varied with the gap distance between $\mathrm{Cu}$ electrodes, but mostly occurred at or near and along the mid bondline not through thickness regardless of the gap distance, so the test was validated for determining the through-bondline $V_{B}$.
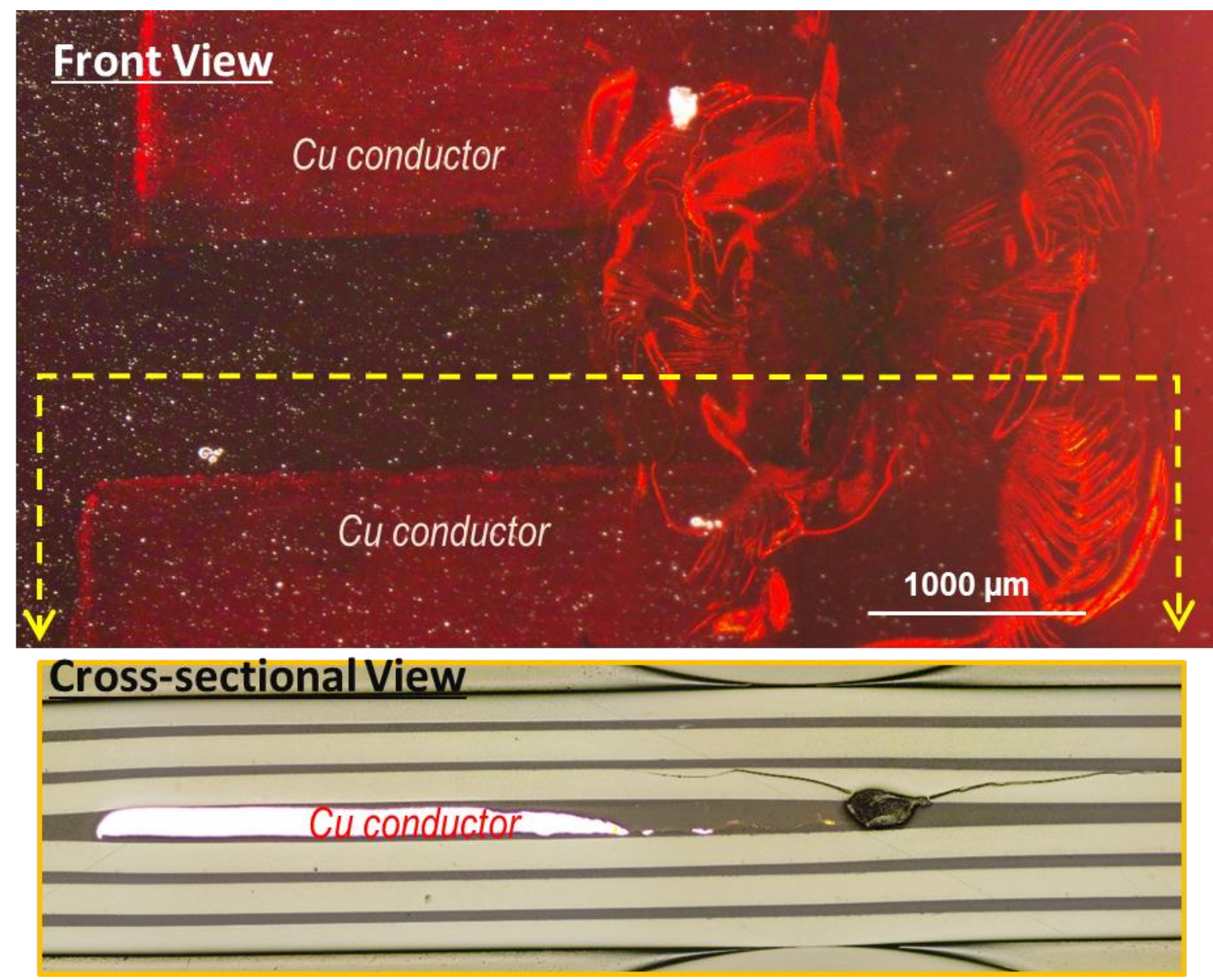

Figure 21. Typical dielectric breakdown failure mode through interfacial bondline.

The test results are summarized in Figure 22 as a function of the gap distance and also compared to the throughthickness $V_{B}$ of PFA in terms of overall thickness. As expected, the through-bondline $V_{B}$ increased with increasing gap distance, but at much slower rate than the through-thickness $V_{B}$. It was also clear that the through-bondline $V_{B}$ was significantly lower than the through-thickness $V_{B}$ of PFA certainly due to imperfection of heat fused bondline even though its bonding integrity was proven to be better than any other bonding methods. In any case, it could be decided that, for the $40 \mathrm{kV}$ requirement, the inter-conductor spacing/gap should be more than $3.6 \mathrm{~mm}$ from the trendline, but rather be $5 \mathrm{~mm}$ for an optimum performance with a safety factor consideration.

Based on the analysis and by adopting the BS22 configuration, overall dimensions of the two MMEI options were determined as summarized in Table 2 and compared to those of the GORE cable. Particularly, the web widths between conductor pods of the two options to withstand $40 \mathrm{kV}$ were determined to be 4.2 and $3 \mathrm{~mm}$, respectively, which were slightly longer than that of the GORE cable. However, the overall diameters of the MMEI pod cables were $3.49 \mathrm{~mm}$ for the option 1 and $3.95 \mathrm{~mm}$ for the option 2 which were much smaller than that of the GORE cable, $5.98 \mathrm{~mm}$, due to their thinner insulation thicknesses, thus significant volume and weight reductions would be achieved from the MMEI options. Performance of the cables will be evaluated by dielectric break down voltage from Hipot or

American Institute of Aeronautics and Astronautics 
progressive stress test (PST), corona PD resistance, and durability under more comprehensive synergistic in-service environment simulation in future. For such performance evaluations, fabrication of $\sim 1 \mathrm{~m}$ long cables is planned for the MMEI options.

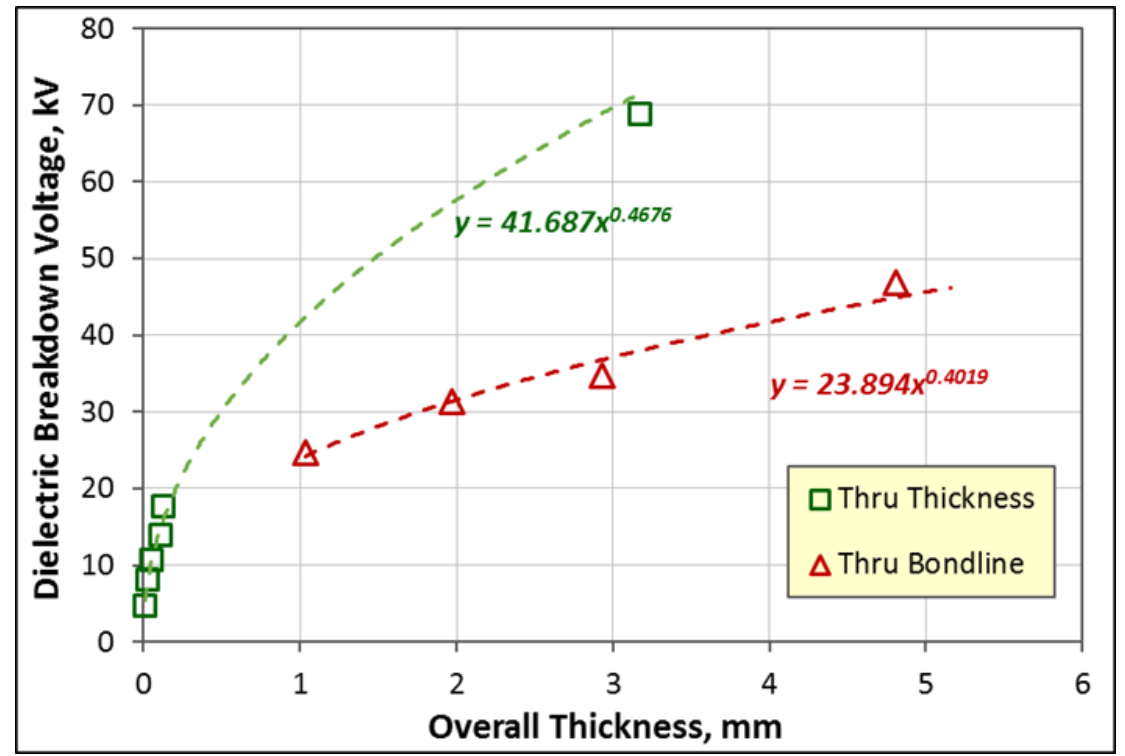

Figure 22. Dielectric breakdown voltages through PFA bondline compared to those through-the-thickness of PFA.

Table 2. Optimum dimensions of MMEI options compared to those of GORE cable.

\begin{tabular}{|c|c|c|c|c|c|c|c|}
\hline \multirow{2}{*}{\multicolumn{2}{|c|}{$\begin{array}{l}\text { Flat cable with } 6 \text { high voltage conductors } \\
\text { AWG } 4 \text { equivalent }(0.25 \mathrm{MWatt} @ 40 \mathrm{kV}+)\end{array}$}} & \multicolumn{2}{|c|}{ GORE } & \multicolumn{2}{|c|}{ MMEI Type I } & \multicolumn{2}{|c|}{ MMEI Type II } \\
\hline & & \multirow{2}{*}{\begin{tabular}{|l|}
$\mathrm{TH}, \mathrm{mm}$ \\
\end{tabular}} & \multirow{2}{*}{\begin{tabular}{|r|} 
OD, $\mathrm{mm}$ \\
2.70 \\
\end{tabular}} & \multirow{2}{*}{$\mathrm{TH}, \mathrm{mm}$} & \multirow{2}{*}{\begin{tabular}{r|}
$\mathrm{OD}, \mathrm{mm}$ \\
2.70
\end{tabular}} & \multirow{2}{*}{$\mathrm{TH}, \mathrm{mm}$} & \multirow{2}{*}{$\frac{\mathrm{OD}, \mathrm{mm}}{2.70}$} \\
\hline Conductor: & $\begin{array}{l}\text { AWG } 10(37 / 0.404 \mathrm{~mm}) \\
\text { Ni plated copper }\end{array}$ & & & & & & \\
\hline \multirow[t]{3}{*}{ Insulation: } & PTFE-PTFE Composite & 1.34 & 5.38 & & & & \\
\hline & MMEl: modified BS22 & & & 0.394 & 3.49 & & \\
\hline & MMEI: modified BS22 & & & & & 0.381 & 3.46 \\
\hline \multirow[t]{2}{*}{ Jacket: } & PTFE, Corona resistant & 0.3 & 5.98 & & & & \\
\hline & 5*PFA+5*PTFE & & & & & 0.254 & 3.97 \\
\hline Web width: & & 2.0 & & 4.2 & & 3.0 & \\
\hline Web thickness: & & 0.6 & & 0.787 & & 0.508 & \\
\hline Final Cable & & & 5.98 & & 3.49 & & 3.97 \\
\hline Overall width, $\mathrm{mm}$ & & \multicolumn{2}{|c|}{53.5} & \multicolumn{2}{|c|}{51.2} & \multicolumn{2}{|c|}{41.8} \\
\hline
\end{tabular}

2. High Voltage High Frequency Bus Bar

In collaboration with MERSEN (MERSEN New Product Development, Rochester, NY), a meter-long bus bar prototype has been developed for high voltage (maximum operating voltage of $20 \mathrm{kV}$ but designed for $40 \mathrm{kV}$ ) and high frequency $(400 \mathrm{~Hz}$ up to $4000 \mathrm{~Hz}$ ) application. It was targeting operating power of $1 \mathrm{MW}$ up to $10 \mathrm{MW}$ and operating temperature up to $180{ }^{\circ} \mathrm{C}$ as a three-phase system as shown in Figure 23 with simple inputs/outputs at both ends or sides. The example cross-sectional diagram also listed some suggested potential insulation materials, but any Class $\mathrm{H}$ or $\mathrm{C}$ insulation can be acceptable, but the overall designs will be optimized in terms of test specifications and requirements relevant to actual in-service environmental conditions, e.g., altitude pressure, moisture, and mechanical vibration etc. The recommended dimensions of the prototypes were 3.0 inch wide and 39.4 inch ( $1 \mathrm{~m})$ long with 0.125 inch thick aluminum (1100-H14 or equivalent). Two sets of blank conductor samples are available for the second

American Institute of Aeronautics and Astronautics 
prototype with the new MMEI system to be fabricated at NASA. Similar to the cable case, efforts are being made to develop the best design and fabrication method-procedure how to apply the MMEI system for the NASA bus bar prototype. Performance of both prototypes will be evaluated and compared via electrical Hipot and corona PD testing as well as durability testing under more comprehensive synergistic in-service environment simulations in future.

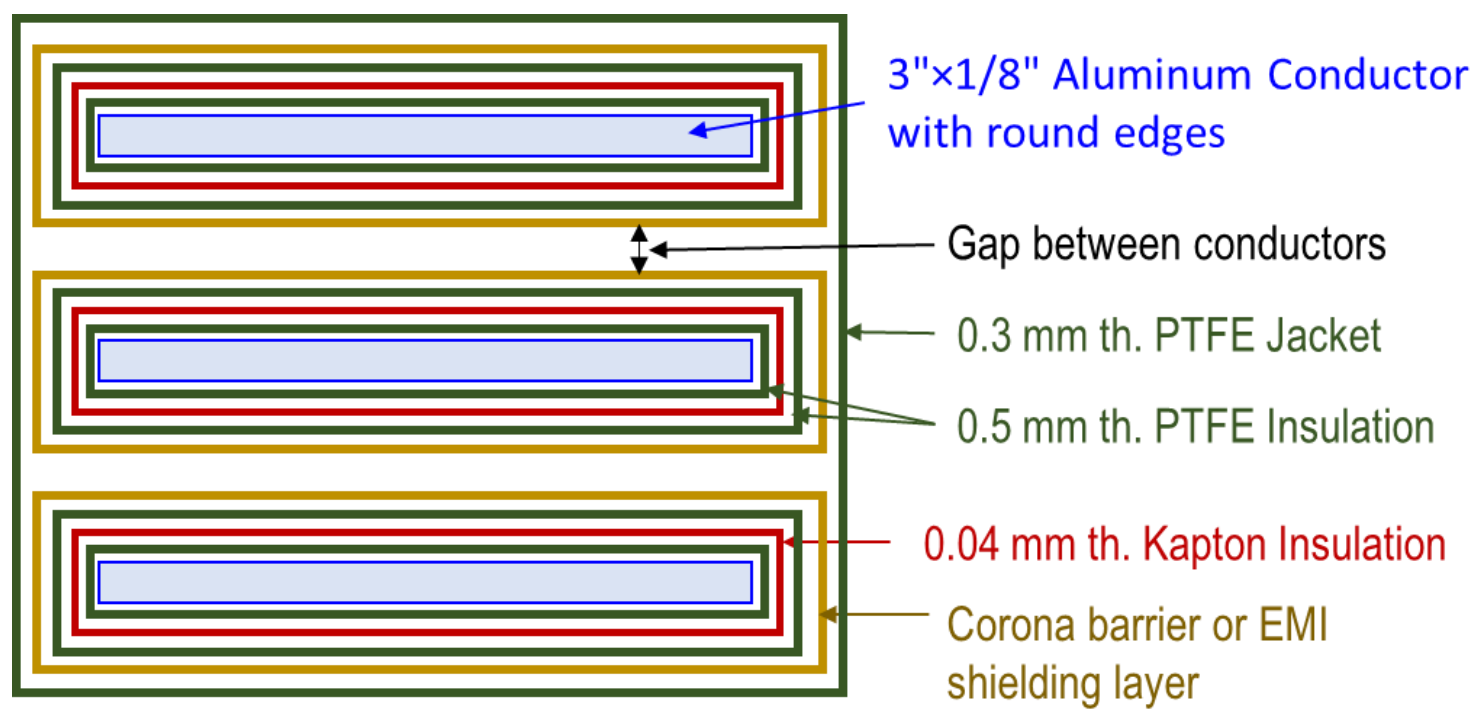

Figure 23. Example cross section of HVHF bus bar prototypes to be developed by MERSEN.

\section{Summary and Conclusions}

Micro-multilayer structures of well-known polymer insulation materials, namely MMEI, were newly developed and evaluted for high voltage insulation, up to $40 \mathrm{kV}$ or higher. Based on extensive evaluations to date, key findings are as follows:

- MMEI structures with various Kapton PI materials and PFA or PET as a bond layer achieved $61 \%$ increase in $V_{B}$ or $K$ compared to that of Kapton PI alone films including the SOA TKT, thus resulted in $86.3 \%$ decrease in insulation thickness.

- Dielectric performance of MMEI structures was governed by various material, process, and structural parameters, such as dielectric properties of constituent materials, inter-layer bonding integrity, overall thickness, total number of layers or interface, individual layer thickness, and ratio of constituent materials.

- Good inter-layer bonding integrity produced significantly higher $V_{B}$ or $K$.

- $K$ of the MMEI structures increased with (i) decreasing individual layer thickness regardless of material type, (ii) increasing total accumulated thickness of PI or overall PI/BL ratio, and (iii) increasing number of interface or total number of layers, but only above the overall thickness limit of $0.15 \mathrm{~mm}$.

- Contribution of Kapton PI on overall MMEI dielectric performance was greater than that of PFA or PET, and as a bond layer, PFA performed better than PET.

- For a given overall thickness, the failure mode seemed to change from more catastrophic mode involving cracking, cavitation, charring, PP or THP in single polymer insulation films to more gradual or progressive mode involving microcracking, cavitation, melting, channeling, debonding, interfacial swelling, charring and PP in the new MMEI structures.

- Dielectric breakdown failure of MMEI structures proceeded with a progressive damage evolution involving more damage types/events and larger damage zones, which suggested that more energy was involved in the breakdown process, thus resulted in the higher dielectric strength.

- Material modifications, typically via addition of fillers or additives, decreased $K$ in either PI alone film or MMEI structures since the fillers or additives, especially their interfaces with matrix material, acted as defects.

- Various responsible mechanisms for the significant property improvement of the new MMEI system were postulated, but should be validated experimentally. 
- Improvement of processing conditions/procedures, e.g., more accurate and uniform control of fusebonding temperature, compression loading at processing temperature, and cleanliness, granted additional increase of $V_{B}$ or $K$ in various MMEI structures, but thinner structures below the limitation, $0.15 \mathrm{~mm}$, was less affected by the processing conditions.

Design and more systematic performance evaluations of the scaled up MMEI systems were initiated y in order to validate their practicality and applicability via direct comparison with those of the SOA commercial high voltage power transmission systems including GORE's HV power pod cable and MERSEN's HVHF bus bar prototypes.

- $\quad V_{B}$ of GORE cable was measured successfully using the GRC dielectric strength tester after optimizing configuration of the cable test coupon.

- Two options for applying MMEI system to GORE pod cable were developed including determination of optimum dimensions, fabrication methods and procedures.

- In collaboration with MERSEN, a meter-long bus bar prototype has been developed for high voltage (maximum operating voltage of $20 \mathrm{kV}$ but designed for $40 \mathrm{kV}$ ) and high frequency ( $400 \mathrm{~Hz}$ up to 4000 $\mathrm{Hz}$ ) application. Design and fabrication procedures for applying MMEI system to the same blank bus bar are being developed.

\section{Future Work Plan}

The following tasks are planned to continue for development and improvement of the MMEI system:

- Material-design-process optimizations, especially for multifunctionalities including inorganics, ceramics, or metals

- Scale up and commercialization feasibility assessment

- More sophisticated performance evaluations of the MMEI structures including synergistic durability assessment

- Experimental validation of potential mechanisms on performance enhancement of MMEI structures

\section{Acknowledgments}

The authors would like to thank our industrial collaborators, W. L. GORE \& ASSOCIATES, INC., Landenberg, PA and MERSEN New Product Development, Rochester, NY. Special thanks to A. Woodworth, Janet Hurst, and the rest of project team at GRC. This work has been sponsored by NASA's Convergent Aeronautics Solutions (CAS) program initially and by Transformational Tools and Technology (TTT) program currently.

\section{References}

[1] Rohn, D. A., Barhydt, R., “Transformative Aeronautics Concepts Program_Overview and CAS Project Details,” September 26, 2014, http://sites.nationalacademies.org/cs/groups/depssite/documents/webpage/deps_152308.pdf.

[2] Welch, G.E., "Overview of CAS HEP Activities at GRC," GRC CAS Project Office, March, 2016, http://www.nianet.org/ODM/ODM\%20Tuesday\%20presentations\%20Final/20\%20Welch\%20Overview\%20of\%20CAS\%20 HEP\%20activities\%20at\%20GRC\%20for\%20ODM\%20workshop\%20Mar\%208-9,\%202016.pdf.

[3] Rosario, R.D., "Next Generation Aircraft Electrical Power Systems \& Hybrid/All Electric Aircraft," Aerospace Electrical Systems Expo, Long Beach, California, May 20, 2015, https://ntrs.nasa.gov/archive/nasa/casi.ntrs.nasa.gov/20150022418.pdf.

[4] Jansen, R., Bowman, C., Jankovsky, A., "NASA Hybrid Electric Propulsion," Tri-Service Energy Optimized Aircraft (EAO) Steering Committee Meeting, May 17, 2016.

[5] Bowman, C., "Visions of the Future: Hybrid Electric Aircraft Propulsion," AIAA Aircraft Electric/Hybrid-Electric Power \& Propulsion Workshop, July 28, 2016, https://ntrs.nasa.gov/archive/nasa/casi.ntrs.nasa.gov/20170002633.pdf.

[6] Dyson, R., "NASA Hybrid Electric Aircraft Propulsion," NIEA Biomimicry Summit, Cleveland, OH, Oct. 4, 2017, https://www.grc.nasa.gov/vine/wp-content/uploads/sites/91/Rodger-Dyson-NASA-Hybrid-Electric-Aircraft-Propulsion-10-42017-FULL.pdf.

[7] Antcliff, K. R., Moore, M. D., and Goodrich, K. H., "Silicon Valley as an Early Adopter for On-Demand Civil VTOL Operations," 16th AIAA Aviation Technology, Integration, and Operations Conference, 13-17 June 2016, Washington, D.C. https://arc.aiaa.org/doi/abs/10.2514/6.2016-3466

[8] NASA announcement, https://www.nasa.gov/aero/nasa-embraces-urban-air-mobility

[9] Zhang, X., Bowman, C. L., O'Connell, T. C., Haran, K. S., "Large electric machines for aircraft electric propulsion," IET Electric Power Applications, The Institution of Engineering and Technology Journals, ISSN 1751-8660, January 15, 2018.

[10] Simoni, L., "A general approach to the endurance of electrical insulation under temperature and voltage." IEEE Transactions on Electrical Insulation(4): 277-289., 1981.

[11] Christou I., "Optimisation Of High Voltage Electrical Systems For Aerospace Applications," Thesis for the Ph.D. degree, School of Electrical and Electronic Engineering, The University of Manchester, 2011.

American Institute of Aeronautics and Astronautics 
[12] Cinibulk W., “Aircraft Electrical Wire _ Wire Manufacturers Perspective," Tyco Electronics (Raychem), via online at https://www.mitrecaasd.org/atsrac/FAA_PI-Engineer_Workshop/2001/aircraft_electrical_wire.pdf.

[13] Kurek, J., Bernstein R., Etheridge M., LaSalle G., McMahon R., Meiner J., Turner N. Walz M., and Gomez C., “Aircraft Wiring Degradation Study," DOT/FAA/AR-08/2, U.S. Department of Transportation, Federal Aviation Administration, Air Traffic Organization Operations Planning, Office of Aviatin Research and Development, Washington, DC 20591, January 2008

[14] Lizcano, M., "Multilayered Functional Insulation System (MFIS) for AC Power Transmission in High Voltage Hybrid Electrical Propulsion," The 2017 EnergyTech Conference and Expo, Cleveland, OH, Oct 30 - Nov 02, 2017

[15] DUPONT ${ }^{\mathrm{TM}}$ KAPTON ${ }^{\circledR}$ SUMMARY OF PROPERTIES, http://www.dupont.com/content/dam/dupont/products-andservices/membranes-and-films/polyimde-films/documents/DEC-Kapton-summary-of-properties.pdf,

and http://www.dupont.com/content/dam/dupont/products-and-services/membranes-and-films/polyimde-films/documents/DECKapton-general-specs.pdf.

[16] CIRLEX $^{\circledR} \quad$ Technical Data Sheet, FRALOCK ${ }^{\circledR}, \quad$ A Division of Lockwood Industries Inc., http://www.cirlex.com/CIRLEX\%20technical\%20data\%201.pdf.

[17] E.E.Shin, A.Hiltner, and E.Baer, "The Brittle-to-Ductile Transition in Microlayer Composites", J. of Applied Polymer Science, 47, p269, 1993.

American Institute of Aeronautics and Astronautics 